\title{
José Mármol und die englischsprachige Romantik
}

Ich möchte die Generation der jungen argentinischen Proscriptos nach Esteban Echeverría und Domingo Faustino Sarmiento nun vervollständigen, indem ich Sie mit José Mármol bekannt mache, der von 1818 bis 1871 lebte. Wie, sie kennen ihn schon? Ja, ich hatte mich mit dem ersten von drei blinden Direktoren in der Geschichte der argentinischen Nationalbibliothek bereits in meiner Vorlesung LiebeLesen auseinandergesetzt; ${ }^{1}$ dort freilich in einem anderen Kontext, den ich in diesem Kapitel und in Zusammenhang mit den beiden anderen argentinischen Schriftstellern komplementär ergänzen will. Wir wissen bereits, dass er wie Sarmiento nach dem Sturz der Rosas-Diktatur im Februar 1852 nach Argentinien zurückkehren, wie viele seiner Generation an die politische Macht kommen und wichtige Ämter innerhalb des labilen Nationalstaats einnehmen sollte.

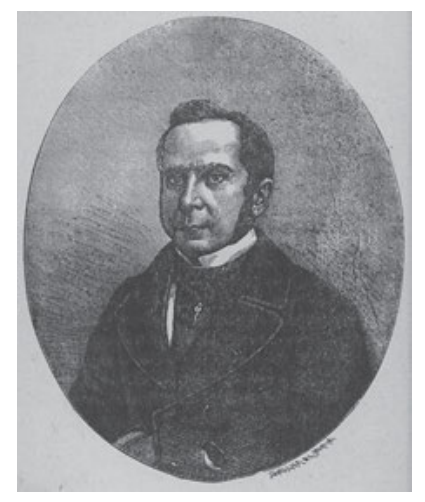

Abb. 55: José Mármol (Buenos Aires, 1817 - ebenda, 1871).

Wie Echeverría und Sarmiento orientierte sich auch Mármol in seinem Schreiben grundsätzlich am ersten Pol unseres kulturellen Modells, mithin an der vorbildgebenden iberischen Kultur im Kontext ihrer abendländischen Traditionsstränge. Bei unserer Analyse wird sich zeigen, dass sich der Autor des Romans Amalia in starkem Maße und durchaus typisch für die Area des Río de la Plata an den Entwicklungen innerhalb der englischen Literatur ausrichtete und dieser Variante des ersten Pols eine hohe Bedeutung gab. All dies erfolgte im Zusammenhang all jener Diskussionen der Proscriptos über den zu schaffenden modernen Nationalstaat, mit dem man Argentinien, das über die üppigsten Bodenschätze verfügt und sicherlich per se das reichste Land Südamerikas darstellt, endlich in eine perfekte Startposition für das 19. Jahrhundert bringen wollte. Bei diesen Über-

1 Vgl. Ette, Ottmar: LiebeLesen, S. 496-528. 
legungen und Zukunftsvisionen spielte die Frage einer erhofften europäischen, vor allem mittel- und nordeuropäischen Einwanderung nach Argentinien eine zentrale Rolle.

Doch was auf der konkreten politischen und gesellschaftlichen Ebene europäische Einwanderung bewerkstelligen sollte, nämlich Argentinien endlich in eine rasche wirtschaftliche und soziale Entwicklung zu katapultieren, das musste der Ideentransfer auf literarischer beziehungsweise ästhetischer Ebene, selbstverständlich unter den Vorzeichen eines geokulturellen Dominantenwechsels mit neuer Ausrichtung an England und Frankreich, in die Wege leiten. José Mármol war in dieser Frage optimistisch.

Doch die Pläne der ins Exil gejagten argentinischen Intelligenzija hatten auch eine überaus dunkle Schattenseite: Denn sie radikalisierten die Ausrichtung am ersten Pol unseres Schemas. Von einer Radikalisierung ließe sich insoweit sprechen, als bislang marginalisierte kulturelle Pole nicht länger nur randständig bleiben, sondern brutal ausgeschlossen oder gar in die Vernichtung getrieben werden sollten. Das Motto des 1810 in Tucumán geborenen Juan Bautista Alberdi vom „Gobernar es poblar“, vom „Regieren heißt bevölkern“, meinte im Grunde eine Einwanderungspolitik, in welcher das Bevölkern mit europäischen Immigranten vorzugsweise nicht-spanischer Herkunft einher gehen musste mit einem Entvölkern von indianischen Gruppen - eine Position, der sich Sarmiento literarisch wie politisch zugehörig fühlte und für die er offensiv warb.

Aus einer derartigen Perspektive erschienen schwarze Kulturen nicht als kulturtragende Elemente des künftigen Argentinien, sondern mussten nach Ansicht dieser Gruppe als Zeugnisse einer Barbarei, die es auszumerzen gelte, schnellstmöglich beseitigt werden. $\mathrm{Zu}$ dieser Ansicht trat ein kurzfristiger politischer Aspekt mit hinzu, insofern die Schwarzen mehrheitlich auf Seiten der Rosas-Getreuen gekämpft und zu dessen heftigsten Anhängern gezählt hatten. Der volkskulturelle Pol rückte - wie wir sahen - durchaus in Gestalt der Gauchos ins Blickfeld, wurde aber zusammen mit dem Spanischen zugunsten der neuen kulturellen Zielvorstellungen, die deutlich im nicht-spanischen Europa lagen, ebenfalls ausgegrenzt. Man versuchte, ihre Zahl und damit ihren Bevölkerungsanteil zu dezimieren, indem man sie als Kanonenfutter in den Kriegen gegen die indigene Bevölkerung einsetzte und bewusst aufrieb.

Kulturelle Misch- und Hybridformen, die bei Sarmiento sehr wohl einen breiten Raum einnehmen, obwohl sie kulturell nicht als nationalstaatlich tragfähig erachtet werden, fristen ein marginales Dasein im politischen wie im literarästhetischen Spektrum: José Mármols Amalia bildet, wie wir gleich sehen werden, hierin keine Ausnahme. Überhaupt sind die Positionen der argentinischen Proscriptos von überraschender Homogenität und werden von denselben Darstellungsweisen wie von identischen Zielstellungen bestimmt. All dies 
gibt uns Hinweise genug auf die Tatsache, dass das kulturelle Projekt, das der jungen argentinischen Generation, den jungen Rebellen und Rosas-Gegnern vorschwebte, alles andere als revolutionär war. Dieses letztlich erfolgreich durchgesetzte Vorhaben plante die Fortführung der politischen Unabhängigkeit unter Beibehaltung einer mentalen und literarischen Abhängigkeit, wobei „Independencia“ und „Patria“ von den Vertretern des argentinischen Exils ständig auf den Lippen geführt wurden. Diese,Geburtsfehler' des kulturellen Projekts der argentinischen Proskribierten sollten wir ernst nehmen und in unseren Überlegungen berücksichtigen!

José Mármol gehört - wir haben es schon erwähnt - der Gruppe dieser Proscriptos an; und zwar jener des uruguayischen Exils, also des eigentlichen Zentrums des argentinischen Exils in Montevideo, gleichsam mit dem distanzierten Blick aus der Nähe des La Plata. Er hatte dessen Meeresarm 1840 überquert, zur Zeit des Höhepunktes des Terrors der Rosas-Diktatur und kurz nachdem er selbst in Buenos Aires das Gefängnis für einige Zeit kennenlernen musste. Wie Echeverría war auch er auf einer französischen Fregatte ins Exil entkommen. Seit 1838 - wir erinnern uns - hatten die Franzosen die Rosas-Regierung mit einer Seeblockade belegt, die auch in Amalia eine gewisse Rolle spielen wird.

In eben jenem Jahr 1840, in welchem der dreiunddreißigjährige Mármol das rettende Gestade Uruguays erreichte, sind die Ereignisse des Romans angesiedelt; genauer noch zwischen dem 4. Mai und dem 5. Oktober 1840. Und sie beginnen mit dem scheiternden Versuch einiger Argentinier, zur Flucht über den La Plata aufzubrechen und dem Rosas-Regime im wahrsten Sinne des Wortes den Rücken zu kehren. Dies weist unmissverständlich auf zwei wichtige Aspekte dieses Romans hin: erstens auf einen historischen und realgeschichtlichen Bezug, dem eine nur geringe zeitliche Distanz eignet; und zweitens auf eine stark autobiographische Grundtönung, welche den Roman, also die Fiktion auf einer realen Erfahrung der erlebten realhistorischen Geschichte aufruhen lässt. Auf diesen autobiographischen wie auf den historisch-politischen Grundzug des Romans werde ich noch mehrfach zurückkommen.

Der Roman Amalia von José Mármol erschien 1851, elf Jahre nach den historischen Ereignissen und vor allem der politisch und sozial unterfütterten Romandiegese, zu welcher die Fiktion einen engen Bezug aufweist. Er erschien im Feuilleton des von José Mármol selbst herausgegebenen Periodikums La Semana in Montevideo. Bis zu diesem Zeitpunkt war sein Verfasser vor allem als Lyriker bekannt: 1841 etwa hatte er sich erfolgreich an einem „Certamen“ in Montevideo beteiligt. Daneben schrieb er Theaterstücke und politische Prosa, die auch in seiner eigenen Zeitschrift gegen die Rosas-Diktatur agitierte. In diesen Kontext gehört Amalia ohne Zweifel; als die Opposition gegen Rosas gegenstandslos wurde, büßte der argentinische Autor einen großen Teil seiner Kreativität ein. 
1855 erschien der nochmals überarbeitete und dem Ende der Rosas-Diktatur angepasste Roman in Buchform.

In Amalia wird die Sarmiento'sche Opposition zwischen Zivilisation und Barbarei in eine Romanfabel umgestrickt und anders als in Esteban Echeverrías El Matadero auf eine ganze Nation bezogen. Der Nationenbildungsprozess erscheint als Allegorese in der tragischen Liebesbeziehung, die dem gesamten Roman ähnlich wie in La Cautiva - die diskursive Grundstruktur und mehr noch den erzählerischen Treibstoff verschafft. In unserer Vorlesung LiebeLesen hatten wir uns ausführlich mit der ungeheuren Macht beschäftigt, mit welcher die Liebe den gesamten Roman als Sinnbild der Nation befeuert. Wir können diesen Aspekt im Folgenden also vernachlässigen: Nation und Narration gehen auch hier zusammen und vereinigen sich in der Gestalt der schönen Titelheldin, die zu einer der großen romantischen Figuren des argentinischen und lateinamerikanischen Romans avanciert.

Zweifellos ist Mármols Amalia ein historischer und ein politischer Roman zugleich. Die Bezugnahme auf Traditionen des englischen Romans und insbesondere auf den historischen Roman im Sinne Walter Scotts ist offensichtlich. Originell freilich ist José Mármol insoweit, als er die große Nähe zwischen erzählter Zeit und Erzählzeit dadurch künstlich ausweitet, indem er seinen Erzähler auf Ebene der Erzählzeit eine große zeitliche Distanz zum Geschehen aufbauen lässt. Sie wird in ihrem Verhältnis zur erzählten Zeit folglich in die Zukunft verlagert, so dass man angesichts des dadurch erzeugten fiktiven Abstands zum Geschehen mit einigem Recht von einem historischen Roman sprechen kann. Zugleich reiht er sich in eine andere Romantradition ein: Denn im Kontext der großen Werke argentinischer Erzählliteratur ergibt sich eine klare Entwicklung hin zur „Novela de dictadores“. In El Matadero ist der Diktator überall anwesend aber nirgends sichtbar, im Facundo ist er gleichsam metonymisch verschoben hinter der Figur des Caudillo versteckt, um schließlich in Mármols Amalia dann zu einer wichtigen Romanfigur zu werden. Diese wurde vom Romancier nach allen Regeln der Kunst - und damit auch der Geschichte - gestaltet. Amalia zog damit die romantechnischen Konsequenzen aus früheren Texten und eröffnet den Weg für eine der fruchtbarsten Subgattungen lateinamerikanischer Erzählkunst, die im 20. Jahrhundert mit berühmten Texten von Asturias, Roa Bastos, García Márquez, Fuentes oder Vargas Llosa eine weit über Lateinamerika hinausstrahlende Blüte erleben sollte.

Der aus insgesamt fünf Teilen bestehende Roman setzt im ersten Kapitel des ersten Teils genau am 4. Mai 1840 mit der nächtlichen Szenerie eines Fluchtversuchs edler argentinischer Männer ins Exil ein, der durch Verrat und bösartige Hinterhältigkeit scheitert und in einem Blutbad endet. Denn die Schergen des Regimes antworten mit Mord auf diesen Versuch, den man hierzulande wohl 
als ,Republikflucht' bezeichnet hätte. So findet bereits in dieser ersten Szene ein blutiger Kampf zwischen Zivilisation und Barbarei statt - so jedenfalls die Einordnung der Geschehnisse durch den Erzähler. Eduardo Belgrano, Sohn des berühmten argentinischen Generals Belgrano, kann dem Blutbad entkommen und rettet sich dank der Hilfe seines Freundes Daniel Bello in die Nacht. Eduardo ist wie alle Unitarier von großer äußerer Schönheit, die selbstverständlich auf seine hohen inneren Werte und damit seine moralische Überlegenheit verweist. Er kann sich ins Haus der nicht weniger attraktiven Amalia retten, die als Kusine seines Freundes Bello mit ihrer Schönheit für dieselben Werte der Freiheit einsteht. Nun, schön und schön gesellt sich gern; und Sie können sich die romantische Liebesbeziehung vorstellen, die zwischen beiden erwacht ...

Der hübsche Eduardo wird im Kampf mit den feigen, aber zahlreichen Mordbuben verwundet und schreit seinen künftigen Mördern zum ersten Mal „Barbaren“ ins Gesicht. ${ }^{2}$ Argentinien ist tief gespalten zwischen den Anhängern der Rosas-Diktatur und damit der Barbarei und den Verteidigern der Freiheit, der Menschenwürde und Zivilisation, die allesamt wie der Autor ins Exil gehen müssen. Sag' mir, was Du liest, und ich sage Dir, was du bist: Gleich zu Beginn erfahren wir, dass Amalia Alphonse de Lamartines Méditations liest, ${ }^{3}$ mit denen wir uns später noch beschäftigen werden! Der Anblick der jungen Frau bezaubert den schwerverwundeten Eduardo, der sogleich ,in einer Frau von zwanzig Jahren eine bezaubernde Physiognomie“ wahrnimmt: „eine majestätische und ebenmäßige Stirne, braune Augen voller Ausruck und Gefühl sowie eine schöne Figur“, wobei ein „schwarzes Gewand dafür gewählt schien, das strahlende Weiß ihres Busens und ihrer Schultern hervorzuheben“.4

Amalia ist mit allen Wassern der Romantik gewaschen und entspricht dem Idealbild einer liebenden romantischen Frau - nicht nur in Lateinamerika. Das hervorstechende Merkmal dieser Frauengestalt ist die Blässe der romantischen Heldin, die sich kontrastiv vom schwarzen Kleid, aus welchem ihr Körper heraussticht, abhebt und so ihre weiblichen Formen preisgibt. Die junge Frau ist noch in Trauer, ist ihr älterer Ehemann, der ihr laut Erzähler niemals zu nahe trat, doch gerade erst verstorben. Eduardo wird die Trauerzeit etwas verkürzen, doch ist Amalia von Beginn an wie ein Kunstwerk oder Juwel in schwarze Melancholie

2 Mármol, José: Amalia. Prologo de Trinidad Perez. La Habana: Casa de las Americas 1976, S. 15. 3 Ebda., S. 24.

4 Ebda: „para descubrir en una mujer de veinte años una fisonomía encantadora, una frente majestuosa y bella, unos ojos pardos llenos de expresión y sentimiento y una figura hermosa, cuyo traje negro parecería escogido para hacer resaltar la resplandeciente blancura del seno y de los hombros.“ 
gefasst, welche das Ende dieser Liebesgeschichte bereits ankündigt. Die junge, zwanzigjährige Frau ist die liebende Begleiterin und Muse gleichsam zweier Generationen: derjenigen der Väter, die für die Independencia kämpften, und der Generation der Jungen, welche die argentinische Republik vor der Barbarei retten müssen. Amalia ist die Verkörperung Argentiniens und selbstredend stammt die schöne Frau aus Tucumán. ${ }^{5}$

Wichtig ist, dass Amalia nicht allein französische, sondern vor allem auch englische Literatur liest. Sie verkörpert ein gebildetes Argentinien, das sich ,natürlich“ am literarischen Kanon eines modernen Europa jenseits von Spanien orientiert. Noch einmal: Amalia ist, was sie liest! Sie ist die Verkörperung europäischer Ideale auf amerikanischem Boden, Verkörperung dessen, was schon Echeverría und Sarmiento als den Pol der Zivilisation beschrieben.

Es ist keine Frage, dass die transareale Beziehung zwischen Lateinamerika und Europa von einer grundlegenden Asymmetrie geprägt ist, welche aus dem europäischen Kolonialismus erwächst. ${ }^{6}$ Die Ausrichtung der jungen Frau literarisch und kulturell - an Europa fügt sich folglich in eine Vektorizität ein, welche nicht allein von einer scharfen Asymmetrie ,zwischen den Welten' geprägt ist, sondern zugleich ein transatlantisches spanischsprachiges Zusammenspiel entstehen lässt, aus dem sich in einem allgemeinen Sinne die Romanischen Literaturen der Welt entwickeln. Die Asymmetrie ist noch mit Händen greifbar, da Amalia nicht schreibt, sondern liest - und sie liest auch keine argentinische, keine amerikanische, sondern vielmehr europäische Literatur. Doch an dieser Stelle gerät nach der formalen, politischen Independencia der entstehenden hispanoamerikanischen Staaten etwas in Bewegung, was bereits als Sattelzeit jener Entwicklungen gedeutet werden darf, die zur wichtigen Rolle lateinamerikanischer Schriftstellerinnen und Schriftsteller im 20. Jahrhundert sowie zur Ablösung einer europazentrierten Weltliteratur durch eine multipolare Strukturierung der Literaturen der Welt führen sollte. Amalias Lektüre französischer und englischer Literatur bei José Mármol wird sich schon wenige Jahrzehnte später in einem Roman José Martís in die Lektüre von Mármols Amalia verwandeln und zugleich ein selbstbewussteres Schreiben hervorbringen, das sich in Lateiname-

\footnotetext{
5 Ebda., S. 25.

6 Vgl hierzu Ette, Ottmar: Asymmetrie der Beziehungen. Zehn Thesen zum Dialog der Literaturen Lateinamerikas und Europas. In: Scharlau, Birgit (Hg.): Lateinamerika denken. Kulturtheoretische Grenzgänge zwischen Moderne und Postmoderne. Tübingen: Gunter Narr Verlag 1994, S. 297-326; sowie Ette, Ottmar / Ingenschay, Dieter / Maihold, Günther (Hg.): EuropAmerikas. Transatlantische Beziehungen. Frankfurt am Main - Madrid: Vervuert - Iberoamericana 2008.
} 
rika der lateinamerikanischen Traditionen wesentlich bewusster ist. ${ }^{7}$ Der Mármol'sche Roman wurde in der Tat recht rasch zu einem Bezugspunkt für Autorinnen und Autoren in Lateinamerika, die nicht länger den innerliterarischen Raum ihrer Erzähltexte allein an Europa ausrichten wollten.

Die TransArea Studien sagen etwas aus nicht allein über die intertextuellen Beziehungen zwischen verschiedenen Kontinenten, sondern auch über die sozioökonomischen Kontexte dieser Beziehungen und über die kulturelle Beschaffenheit der jeweiligen Bezugs- und Zitierweisen. Dass die Herausbildung der Romanischen Literaturen der Welt anfänglich gerade im transatlantischen Bereich sehr stark von kolonialen und postkolonialen Asymmetrien geprägt war, ist ohne jeden Zweifel der Fall. Über die Vektorizität und die Symmetrie, mithin die Wertigkeit dieser Beziehungen, müssen die TransArea Studien Aussagen treffen, welche sich aus den untersuchten Texten selbst ableiten lassen. Die spezifischen Aussagen zur transarealen Intertextualität müssen jedoch eingebettet sein in die Gesamtheit an Literatur- und Kulturbeziehungen, die zum jeweiligen Zeitpunkt innerhalb eines zunehmend globalisierten Literatursystems vorherrschen. Diese Dimension möchte ich auch in die nachfolgenden Überlegungen aufnehmen und in die Vektorizität gerade auch der Romantik zwischen zwei Welten einbringen.

Da der schwerverletzte Eduardo von einem Arzt behandelt werden muss und man keinem in einer Diktatur mehr vertrauen könne, führt José Mármols Erzähler einen gewissen Doktor Alcorta ein; eine historische Gestalt, welcher der argentinische Romancier in diesen Zeilen ein Denkmal setzt. Dieser Alcorta - so erfahren wir - besitze einen Lehrstuhl an der Universität von Buenos Aires und zu seinen Schülern gehörte auch der oben erwähnte Alberdi. Schon in Sarmientos Facundo war ein Doktor gleichen Namens aufgetaucht. Ich möchte dieses Beispiel nur deshalb erwähnen, weil es zum einen die realhistorische, fast dokumentarische Einbettung des Romangeschehens aufzeigt und zugleich einen Hinweis auf die kleine Welt der Rosas-Gegner gibt: Man kennt sich und zitiert sich. Die Gegner des Diktators sind allesamt gebildete Argentinier, die sich mit ihrer Intelligenz und Bildung gegen einen autoritären Herrschaftsstil auflehnen, der alle Gegenargumente mit einem simplen Niederbrüllen, mit ständiger Wiederholung immer gleicher Slogans aus dem Weg räumen will. Autoritäre Systeme und populistische

7 Vgl. zu dieser wichtigen Entwicklung Bremer, Thomas: Amalia liest. Funktionen des Lesens im lateinamerikanischen Roman des 19. Jahrhunderts und die Rezeption der europäischen Romantik (das Buch im Buch). In: López de Abiada, José Manuel / Heydenreich, Titus (Hg.): Iberoamérica. Historia - sociedad - literatura. Festschrift für Gustav Siebenmann. Band 1. München: Fink 1983, S. 139-164; sowie Ette, Ottmar: Apuntes para una orestiada americana. José Martí y el diálogo intercultural entre Europa y América latina. In: Revista de crítica literaria latinoamericana (Lima, Peru) XI, 24 (2ºmestre 1986), S. 137-146. 
Regierungen hatten zum damaligen Zeitpunkt noch keine ,sozialen Netzwerke‘ zu ihren Diensten, aber die Methoden sind doch sehr vergleichbar.

Für eine Frau wie Amalia standen zum damaligen Zeitpunkt nicht wie für Eduardo oder Daniel die Hörsäle der Universitäten offen. Hier musste die Lektüre von Autoren und gerade auch diejenige fremdsprachiger Texte für Ersatz und für ein Bildungserlebnis sorgen, das als gleichrangig bewertet werden kann. Und eben deshalb liest Amalia: Sie repräsentiert jenes Bild einer Frau, wie Gertrudis Gómez de Avellaneda sie beschrieb, die ihren Lektüren nachgeht - eine selbstbewusste Frau, die ihren Lektüren folgt, auch wenn andere Frauen sie als ,Doktorin' verspotten. Amalia steht in einer zutiefst patriarchalischen Gesellschaft mit allen Widersprüchen auch für jene Emanzipation der Frauen, wie sie „Tula“ oder Flora Tristan in unserer Vorlesung repräsentieren. Auch auf diesem Gebiet ist Emanzipation noch fern, aber wir können sehen, wie sich der Weg dorthin im 19. Jahrhundert zu verkürzen beginnt: Wenn die belesenen und kultivierten Unitarier also für die Zivilisation einstehen, so stehen die nicht weniger belesenen Unitarierinnen zugleich für eine Emanzipationsgeschichte von den Männern ein. Und das Bild der aktiven Frau war uns bereits in La Cautiva erschienen.

Gewiss sollten wir nicht vergessen, dass José Mármol Teil jener höchst produktiven argentinischen Elite ist, die von der Diktatur Juan Manuel de Rosas ins Exil getrieben wurde. Er steht für eine relativ homogene Gegen-Ideologie, welche ab 1852 als Sieger im Kampf um die Macht die Geschichte Argentiniens schreiben wird. Diese wird freilich die Geschichte großer Männer sein, an der Amalia als Frau bestenfalls eine helfende, eine dienende Funktion übernimmt. Wir sollten ihr Bild gleichwohl in Erinnerung behalten und werden es noch gegen Ende unserer Vorlesung in der Gestalt Juana Borreros wieder aufnehmen.

Für die Literaturgeschichte des Diktatorenromans ist dann der folgende Teil wichtig: Denn der diskursiven Passage folgt eine deskriptive, in welcher das nicht zufällig von Gauchos und Indios bewachte Haus des Diktators beschrieben wird - das ganze Gegenteil des feinen und kultivierten Interieur, das die Leserschaft zuvor in der Quinta Amalias kennengelernt hatte. Nach dieser Darstellung des kruden Rahmens erfolgt dann der erste Auftritt des „,argentinischen Diktators“, ${ }^{8}$ wie der Erzähler Rosas zu nennen pflegt. Wir erfahren etwas von Rosas' Sprachpolitik und seinem Bemühen, die von ihm erfundenen Sprachregelungen seinen Untertanen einzuhämmern - Sie können sich das in etwa so vorstellen, wie Donald Trump immer und immer wieder im Wahlkampf von ,Sleepy Joe‘ sprach und für sämtliche Probleme stets sprachliche Vereinfachungen zur Hand hatte, die sie für seine Anhänger beseitigten. Bitte entschuldigen Sie, wenn ich

8 Mármol, José: Amalia, S. 48. 
bisweilen diese Vergleiche ziehe; aber selbstverständlich ist es kein Zufall, dass sich autoritäre Regierungen immer wieder derselben Mittel bedienen, auch wenn der noch aktuelle Präsident der USA keine Gauchos und Indios, sondern ,seine“ Cowboys und Proud Boys zu Hilfe ruft!

Übrigens spielt auch bei Rosas die Familie eine wichtige Rolle. Denn bald schon tritt die schöne Tochter des Diktators auf: Manuela Rosas, welcher José Mármol im Übrigen bereits wenige Jahre zuvor ein eigenes Buch gewidmet hatte, das ihr Bild in der Öffentlichkeit wesentlich prägen sollte und die junge Frau in eine Opferrolle hinein stilisierte. An Rosas’ Händen klebt in Mármols Darstellung buchstäblich Blut: das Blut von Unitariern, die er verfolgen und ermorden lässt. So wird der argentinische Diktator in einem nachfolgenden geschichtsphilosophischen Diskurs gar als „Mesías de sangre“ und als Schlag gegen die angeblichen Träumereien der Independencia bezeichnet. ${ }^{9}$ Mármol vergisst nicht, seine Diktatorengestalt mit Charisma auszustatten, sind es doch nicht nur Macht und Gewalt, die seine Anhängerschaft, aber auch manche seiner Gegenspieler faszinieren.

Im Allgemeinen wird bei Mármol eine Romanfigur zunächst beschrieben und porträtiert, dann folgt sofort der Übergang zum Narrativen, das Portrait wird also in Bewegung gesetzt. Dies ist auch die literarische Verfahrensweise bei der schönen Florencia Dupasquier, die sich bei einem Besuch bei Doña María Josefa Ezcurra, der Schwiegermutter oder - wie es hier heißt - „hermana política“ von Rosas, erst durch eine Horde von Mulattinnen und schwarzen Frauen durcharbeiten muss. Ein gewisser Rassismus lässt sich bei Mármol nicht leugnen, ordnet er dem Diktator und damit dem Bösen doch ebenso Indios wie Schwarze zu. Umgekehrt verwundert es nicht, dass indigene oder schwarze Kulturen keinerlei Rolle in seinem Roman spielen. Die schöne Florencia ist Daniel Bellos Engel, ebenso wie Amalia ein himmlisches Geschöpf, wobei stets die äußere Schönheit und Physiognomie einer Weißen für deren innere, moralische Untadeligkeit stehen. Dagegen ist die Beschreibung María Josefa Ezcurras kontrastiv gestellt, wird sie doch auch im Folgenden immer wieder mit Teufel und Hexen, den „brujas de las leyendas españolas“ in Verbindung gebracht. ${ }^{10}$ Die Welt von José Mármol ist fein säuberlich und rassistisch in Schwarz und Weiß aufgeteilt.

Der zweite Teil des Romans setzt mit einem Verweis auf den britischen Reisenden Andrews und einem Zitat aus seinem Werk ein, ${ }^{11}$ der bei Mármol zur Legitimation des eigenen (amerikanischen) Standpunktes dient. Ich möchte Ihnen diesen Beginn nicht vorenthalten:

9 Ebda., S. 61.

10 Ebda., S. 93.

11 Ebda., S. 126. 
„Tucumán ist mit Blick auf die Großartigkeit und Erhabenheit seiner Natur der Garten des Universums“, schrieb Captain Andrews in seiner 1827 in London publizierten Reise nach Südamerika; und der Reisende war mit dieser Metapher, so übertrieben sie auch zu sein scheint, von der Wahrheit nicht weit entfernt.

Alles, was über Luft und Erde die tropische Natur an Grazie, an Überfluss und an Poesie vereinigen kann, findet sich dort miteinander vermengt, so als ob die Provinz von Tucumán der erwählte Ort für die Genien dieses menschenleeren und wilden Landes wäre, das sich von der Magellan-Enge bis nach Bolivien und von den Anden bis nach Uruguay erstreckt.

Sanft, duftend, fruchtbar und an Grazien und Opulenz von Licht, an Vögeln und Blumen übervoll ist die Natur, welche dort den Geist ihrer Geschöpfe mit den Eindrücken und poetischen Perspektiven harmonisch vereint, in welchen sein Leben erwacht und sich entwickelt. ${ }^{12}$

Der 1827 in London veröffentlichte Reisebereicht des Engländers Andrews wirkt wie eine Rechtfertigung für die romantischen Naturbeschreibungen, mit denen Mármol seine Leserschaft erfreute. Wie bei Sarmiento ist es wiederum Tucumán mit seinem subtropischen Klima und seinen Naturschönheiten, welches aus der Gesamtheit des argentinischen Landes hervorsticht. Für die noch immer von Europa abhängige Literaturbetrachtung ist es charakteristisch, dass es der europäische, der englische Text ist, der den spanischsprachigen gleichsam per Zitat legitimiert, verfügt er doch über die Autorität einer innerhalb der Asymmetrie zwischen Europa und Lateinamerika deutlich markierten Diskurshoheit. Daher das Zitat, daher der Verweis auf die Anglizität, daher erst danach die ausufernde, hyperbolische Beschreibung der Landschaft. Diese Beschreibung kann ja nicht irreführend sein, schrieb doch ein Engländer mit all seiner Autorität dieselben überschwänglichen Worte.

Erstaunlich ist es schon - wenn auch höchst erklärlich -, dass es gerade Landschaften sind, die mit europäischen Augen gesehen und von europäischen Augen für schön befunden und legitimiert werden, bevor sie dann als ästhetisierter Hintergrund für eine Handlung dienen, die keineswegs diesen paradiesischen Zuständen entspricht. Wie schon bei Sarmiento und Echeverría gibt es zwischen der Ästhetisierung amerikanischer Landschaften und einer blutrünstigen Handlung, die nach der Landschaftsbeschreibung in den Vordergrund gerückt wird, einen scharfen Kontrast, welcher ganz den Regeln romantischen Schreibens folgt. Allerdings nutzt Mármol einmal auch ästhetisierende Landschaftsbeschreibung als Hintergrund für jene strahlende Schönheit, die seine Titelfigur ausstrahlt und die sie gleichsam mit der amerikanischen Landschaft in eins setzt und verschmelzen lässt. ${ }^{13}$ Amalia erscheint als wundervolle Göttin, wird mit Lucretia

12 Ebda.

13 Ebda., S. 128. 
und Kleopatra verglichen, wird ,antik' semantisiert und literar-erotisch aufgeladen. Die Venus der Medici an Schönheit zu übertreffen, falle ihr nicht schwer, so der Erzähler: Kein Wunder, dass Amalia als Grundbestandteil einer nationalen Allegorese bald für die Schönheit ganz Argentiniens steht!

Die Dialoge des Romans folgen häufig demselben Muster, dessen Grundform sich wie folgt definieren lässt: Einer der Gesprächspartner besitzt einen Wissensvorsprung, der nur schrittweise enthüllt wird. Es handelt sich zumeist um Herrschaftswissen, gerade auch bei Daniel Bello, der ein besonderer Meister in der nur schrittweisen Aufklärung seiner Gesprächspartner ist und damit Umgangsformen aufweist, die keineswegs demokratisch sind oder, sagen wir es anders, zu einer gleichwertigen Partizipation seiner Gesprächspartner an seinen Zielen hinführen. Er ist die überlegene Intelligenz des Romans, doch verkörpert er auch die intelligente Überlegenheit einer moralisch integren Rücksichtslosigkeit, die sich stets im Recht weiß, da die Gegner das Böse verkörpern. Daniel Bellos Freunde sind zumeist hilfebedürftige Kreaturen, die wie etwa Eduardo Belgrano längst in den Fängen des Tigers Rosas geendet und verendet wären.

So aber bleibt das gesamte Geschehen stets in der Schwebe, denn Daniel besitzt immer einen Wissensvorsprung. Der Suspense wird noch dadurch vergrößert und verlängert, dass zwischen die ernsten und gefährlichen Passagen der Handlung zwei komische Figuren und deren Erlebnisse eingeblendet werden: Doña Marcelina, die Besitzerin eines Edelbordells, in welchem vor allem den Federales und Rosas gegenüber willfährige Kleriker verkehren, und Don Cándido, der ehemalige Lehrer Daniels, der stets für eine hasenfüßige Überraschung gut ist. Marcelina und der candide Cándido wiederholen wie in einer Molière'schen Comédie bestimmte ernste Passagen des Romans in Komödien-Tonlage auf niederer Ebene und spannen doch den Leser auf die Folter, da solange das Romangeschehen nicht oder doch kaum vorangetrieben werden kann. Dies sind Verfahren eines europäischen Feuilletonromans, wie sie José Mármol längst auch im Feuilleton seines Periodikums anwandte.

Auch der ehemalige Lehrer Daniels gehört natürlich zu den Schutzbefohlenen des früher von ihm Unterrichteten; er erlebt manch böse Überraschung unter der repressiven Rosas-Diktatur, vor deren Konsequenzen weiterer Schutz von Seiten Daniel Bellos notwendig ist. Eine weitere, nicht unwichtige Nebenfigur ist der Daniel treu ergebene Diener Fermín, bei dem es sich um einen „gauchito civilizado, un buen hijo de la pampa“14 handelt, also einen zivilisierten Gaucho, der als Sohn der Pampa gleichsam domestiziert wurde. Doch auch er ist letztlich

14 Ebda., S. 152. 
nur Instrument in den Händen des alles beherrschenden und gegen den Diktator angehenden Daniel Bello.

Die erste Liebesbegegnung zwischen Amalia und Eduardo steht im Zeichen einer weißen Rose, die zu Boden fällt. Sie symbolisiert die Unschuld der jungen Amalia, was angesichts einer vorangegangenen Ehe im Zeichen des Inzesttabus, der nicht vollzogenen Geschlechtlichkeit nicht weiter verwundert. Sie steht jedoch auch im Kontrast zur schwarzen Kleidung Amalias, deren Alabasterkörper aus der schwarzen Hülle hervorleuchtet. Ihre Augen, ihre leicht geöffneten Lippen: Alles zeigt an Amalia die äußeren Zeichen der Liebe, einer romantischen Liebe, die unter dem Unstern des Tragischen, dem Fatum der gefallenen Rose stehen wird. Auch Amalias schöner Leib ist dem Tode geweiht und sie geht den Schicksalsweg romantischer Heldinnen, denen wir in dieser Vorlesung schon des Öfteren begegnet sind. Amalia weiß sehr wohl, dass es sich um ein schlechtes Vorzeichen handelt. ${ }^{15}$ Damit ist das Lesepublikum vorbereitet und kann das Wiederauftauchen einer weißen Rose an späterer Stelle schneller deuten. Die Assoziierung der schönen Frau mit einer Blume entspricht der genderspezifischen Verrückung alles Weiblichen in die Zyklen der Natur.

In der für die Romantik beider Welten typischen Kontrasttechnik wird diesem gepflegten (Seelen-)Interieur die Atmosphäre eines Balles der Federales gegenübergestellt. Dies ist für den Erzähler (wie für den Autor) eine Gelegenheit zur bösartigen Mocquerie, zum Lächerlich-Machen der Wilden und Barbaren im Lichte der Zivilisierten. Die brillanteste Frau des Balles ist Doña Augustina Rosas de Mansilla, die als schönste Frau ihrer Zeit bezeichnet wird. ${ }^{16}$ Sie wird mit Diana und Rebecca verglichen, dann aber auch negativ konnotiert. ${ }^{17}$ Der unschuldige, aber wunderbare Auftritt Amalias im Zeichen ihrer weißen Rose überstrahlt die föderale Schönheit mit der Grazie der Unitarier. ${ }^{18}$ Selbst auf dem Gebiet weiblicher Schönheit ist beim Erzähler Mármols das Rivalisieren zwischen Federales und Unitarios deutlich.

Denn seine Beschreibungen weiblicher Toilette berühren auch die politische Symbolsprache femininen Schmucks, ist doch das Tragen der föderalen Farben obligatorisch, nicht aber Ort und Größe, die von den Frauen hierzu gewählt werden. Daraus ergibt sich eine ganze Kunst des Details. Wie bei Sarmiento wendet auch der Erzähler in Mármols Roman den symbolischen Aspekten der Kleidersprache große Aufmerksamkeit zu. Auf dem Ball führt eine aristokratische

15 Ebda., S. 156.

16 Ebda., S. 166.

17 Ebda., S. 167.

18 Ebda., S. 173. 
Unitarierin Amalia ein in die Geheimnisse manch opportunistischer föderaler Karriere, etwa jener des Journalisten Mariño, der längst in der Gaceta Mercantil öffentlich das Kehlen-Durchschneiden, das „degollar“von Unitariern fordert, bei diesem Ball aber auch rasch ein entflammtes, aber nicht entflammendes Auge auf die schöne Amalia geworfen hat. Er wird zum von Amalia verachteten, ungeliebten und darum umso mehr mit Hass erfüllten Rivalen Eduardo Belgranos um die schöne Tucumanerin: Damit sind Politik und Liebe endgültig und unentwirrbar im erotischen Spiel um Amalia miteinander verquickt. Mariño verwandelt sich in einen der gefährlichsten Gegner ihrer Liebe und Ziele. Denn er ist nicht nur willfähriges Werkzeug in den Händen des Juan Manuel de Rosas, sondern aktive und agierende Gewalt: ein Machtmensch auf dem Weg zur Erfüllung seines Begehrens.

Mármols romantische Kontrasttechnik betrifft Personen, Personenkonstellationen, aber auch Handlungsstrukturen. Die interessierte Leserschaft bekommt nicht nur einzelne historische Figuren führender Federales, sondern - wie man heute sagen würde - auch die ,Basis` des populistischen Regimes zu sehen. Daniel Bello (und mit ihm das Lesepublikum) nimmt teil an einer Sitzung der Sociedad Popular Restauradora, also an einem Treffen der Parteiclubs der Federales. Wir erhalten dergestalt einen bestimmten Einblick in die Parteilandschaft, auf welcher die Macht des argentinischen Diktators beruht. Natürlich werden ihre Mitglieder völlig ins Lächerliche gezogen: Denn alle Federales sind strohdumm, aber auch blutrünstig und hasserfüllt - das wussten wir bereits aus Echeverrías El Matadero. Damit zeichnen sich schon der weitere Verlauf des Romans und die sich tragisch zuspitzende Geschichte Argentiniens in der ersten Hälfte des 19. Jahrhunderts ab.

Dann jedoch wird diesem Treffen ein von Daniel Bello geleitetes geheimes Treffen der Gegner all dieser Federales gegenübergestellt. Das ist natürlich pure Schwarzweißtechnik: Der geistlosen Sitzung gewalttätiger Dummköpfe wird eine patriotische, hochherzig-noble Versammlung von Unitariern entgegengestellt. Der Farbe Rot wird das Weiß-Blau der „Revolución“ entgegengehalten. Dreihundert bis vierhundert entschlossene Männer würden laut Bello ausreichen, um mit Rosas und der Mazorca in Buenos Aires Schluss zu machen, sobald General Lavalle zur Stadt vorrücke. ${ }^{19}$ Dann werde man die Federales an die Straßenlaternen knüpfen - nicht unbedingt eine Vorstellung, die für die Zivilisation und Kultur der Unitarier spricht!

Daniel Bello geht es darum, jenen Geist der Einheit und Assoziierung zu schaffen, um nicht nur die verhasste Rosas-Diktatur in Argentinien hinwegzufegen, sondern auch in Verbindung mit anderen amerikanischen Staaten $\mathrm{zu}$ treten.

19 Ebda., S. 179. 
Damit setzt er sich ebenso Ziele auf nationaler Ebene wie auf einer lateinamerikanischen Bühne, seien doch die hispanoamerikanischen Länder durch die gemeinsame Independencia und das Christentum miteinander kulturell verbunden. Es gelte daher, schlagkräftige Assoziationen in Buenos Aires zu schaffen, deren Zielsetzungen über Tag und Nation hinausgingen. Die diesbezüglichen patriotischen Reden von Daniel Bello und Eduardo Belgrano erweisen sich als wahre Diskurse im Sinne isotopisch antithetisch strukturierter Bedeutungsgeflechte, wie sie jene junge Generation prägten, der Echeverría, Sarmiento und Mármol als Literaten und politische Denker angehörten. Schauen wir uns daher die Reden der beiden Freunde einmal näher an:

Wollt Ihr das Vaterland, wollt Ihr Institutionen und Freiheit, Ihr, die Ihr Euch die Erben der Erneuerer einer Welt nennt? Nun gut; erinnert Euch daran, dass sie und ganz Amerika eine Vereinigung von Brüdern während des langen Krieges unserer Unabhängigkeit waren, dafür gemacht, gegen den gemeinsamen Feind zu kämpfen, und so vereinigt Euch, um gegen den allgemeinen Feind unserer gesellschaftlichen Erneuerung aufzubegehren: die Unwissenheit; gegen den Entfacher unserer wilden Leidenschaften: den politischen Fanatismus; gegen den Erzeuger unserer Entzweiung, unserer Laster, unserer hasserfüllten Leidenschaften, unseres eitlen und starrsinnigen Geistes: den religiösen Skeptizismus. Denn glaubt mir, uns fehlen Religion, Tugend und Aufklärung, und von der Zivilisation besitzen wir lediglich deren Laster.

Während dieser Rede hatte sich Daniel langsam von seinem Sitz erhoben, und wie von der Energie seiner Worte mitgerissen hatten alle jungen Leute dasselbe getan. Das letzte Wort entschlüpfte den Lippen des jungen Redners, und schon drückten ihn die Arme Eduardos an sein Herz.

Schaut her, Ihr Herren, sagte Eduardo, wobei er seine Augen über die Versammlung der Freunde gleiten ließ, und er behielt seinen linken Arm auf der rechten Schulter Daniels, schaut her: Mein Antlitz ist in Tränen gebadet und die Augen, welche sie vergossen, hatten mit der Kindheit ihre Erinnerung verloren. Könnt Ihr sie erraten? Nein. Die Empfindsamkeit von Euch allen ist von den Worten meines Freundes bewegt, und die meinige ist es angesichts der Zukunft unseres Vaterlandes. Ich glaube an seine Erneuerung, ich glaube an seine Größe und an seinen künftigen Ruhm; aber diese Vereinigung, welche sie am Río de la Plata hervorbringen soll, wird nicht, oh nein, das Werk unserer Generation oder das unserer Kinder sein; und meine Tränen entstehen aus dem schrecklichen und mich beherrschenden Glauben, dass weder ich noch Ihr es sein werden, die am Río de la Plata das strahlende Morgengrauen unserer zivilisierten Freiheit sehen werden, weil uns dafür die Natur, die Gewohnheiten und die Erziehung fehlen, um diese Vereinigung von Brüdern zu bilden, welche allein die Größe des heiligen Werkes unserer Unabhängigkeit in der Generation unserer Väter inspirieren konnte. ${ }^{20}$

Daniel Bellos Rede ist wie Eduardos Ansprache ein schönes Stück hispanoamerikanischer Oratorik und zugleich einer politischen Rhetorik, die bis heute andau-

20 Ebda., S. $183 \mathrm{f}$. 
ert, die Gründungsväter der Independencia ein ums andere Mal anruft und die hehren Ziele von Kultur und Zivilisation preist. Am Ende des Jahrhunderts wird noch einmal in der Figur von José Enrique Rodós Ariel diese lateinamerikanische Festrhetorik aufblitzen. Ihre Wirkung auf die Zuhörer ist bei Bello und Belgrano quasi garantiert, und man dürfte fast dazusagen: Sie ist es bis heute. Es sind in der Tat erhebende Diskurse, die Gewalt über die Körper ausüben und mehr an das Herz als den Verstand appellieren. Es ist eine Redekunst, die den Deutschen nach Ende der Naziherrschaft weitgehend fremd geworden ist, nicht aber den verschiedenen Völkern im romanischen Verbund. Konkrete Vorschläge, präzise Pläne und Angaben finden sich nicht, dafür aber wortreiche Beschwörungen edelster Absichten zum Zwecke einer Niederschlagung personifizierter Monstren und Untiere wie Ignoranz, Fanatismus und Unglauben. Es ist eine Rhetorik, welche mit José Martí und José Enrique Rodó im hispanoamerikanischen Modernismo im 19. Jahrhundert ihre fraglos größten Wirkungen entfalten wird.

Ist Daniels Diskurs gleichsam die überzeitliche Variante, so trägt Eduardos diskursive Ergänzung mit ihren agonalen Zügen unverkennbar die Zeichen der Romantik: nicht nur die öffentlich vergossenen Tränen, die Anrufungen künftiger Größe oder die vielfache Wiederholung des eigenen Glaubens an eine resakralisierte Vaterlandsgestalt; vielmehr vor allem die Betonung des $\mathrm{Zu}$-früh- oder Zu-spät-gekommen-Seins, kurz: ein Gefühl der Deplatziertheit, des rettungslosen Ausgeliefertseins an eine Zeit, die gegen die Erfüllung der eigenen Visionen, der eigenen Träume arbeitet. Immer wieder findet sich der romantische Held nicht an seinem Ort, nicht in seiner Zeit, aus der er wie herausgefallen erscheint.

Freilich ist all dies nicht - wie vielfach in der europäischen Romantik auf literarischer wie politischer Ebene zu beobachten ist - gedacht als Aufstand gegen die Väter, gegen deren ehernes Gesetz die junge Generation der Revolutionäre antritt. Es geht vielmehr um die Verwirklichung von Idealen der Väter, um die Vervollständigung eines amerikanischen Traums von Unabhängigkeit und Freiheit, nachdem der äußere Feind, die spanische Kolonialmacht vertrieben ist. Der Aufschrei Eduardos ist der eines Menschen, der einerseits die Ideale der Ahnen nicht mehr verwirklichen kann, weil er nicht mehr über deren Möglichkeiten verfügt. Andererseits kann er noch nicht so weit sein wie seine Enkel, welche dereinst die Ideale von Freiheit und Unabhängigkeit in Argentinien verwirklichen würden. Eduardo fühlt, dass er zugleich zu früh und zu spät gekommen ist, um in Freiheit seine Liebe leben zu können: Dies ist seine tragische Situation!

Im Diskurs Belgranos blitzt etwas auf von der spezifisch hispanoamerikanischen Erlebnisform romantischer Deplatziertheit, in welcher den europäischen Idealen auf amerikanischem Boden nichts Gleichwertiges bereits verwirklicht entgegengestellt werden kann. Das Aus-der-Zeit-gefallen-Sein Eduardos ist zugleich mit der Erfahrung eines Raumes gekoppelt - seines Raumes in Amerika. Doch 
Lösungen für dieses Problem gibt es nicht. Da bleibt nur der Blick in eine utopisch entworfene große Zukunft, die bis heute stets beschworen wird, wenn es um Diskurse lateinamerikanischer Politiker geht. Wie hatte Bello dies unmittelbar vor der oben zitierten Passage seiner Rede doch formuliert: „die Vereinigung in allem, stets aber, um stark zu sein, um mächtig zu sein, um Europäer in Amerika zu sein. “21

Das Grundgefühl Eduardos, dass seine politischen Träume nicht zu seinen Lebzeiten zu verwirklichen sein würden, steht zum einen mit der bereits diskutierten fiktiven Erzählzeit in Verbindung, insofern diese Aussage aus der Perspektive des Jahres 1851 eine rückwärtsgewandte Prophezeiung darstellt, als selbst für Mármol die Rosas-Diktatur noch nicht überwunden war. Zum anderen entspringt dieses Gefühl aber auch einer Ahnung, dass die Liebe zu Amalia nicht zu einem dauerhaften Glückszustand, einer stabilen Beziehung gebracht werden könne: zu feindlich ist die Umwelt, zu gefährlich der soziopolitische Kontext, in welchem sich die beiden Liebenden im Argentinien der Rosas-Diktatur bewegen. Sie merken, wo hier Liebe zur „Patria“ und Liebe zur geliebten Frau in Deckung gebracht werden sollen: Dies ist die romantische Grundsituation eines Konflikts, der noch bis in die Schriften José Martís, bis in die Liebesbriefe Juana Borreros einen unausweichlichen und zugleich unlösbaren Konflikt zwischen individuellem, persönlichem Glück und kollektiver Nationenbildung darstellt.

Auf beiden Ebenen werden die Liebenden in der Tat scheitern; und dieses Scheitern der Liebesbeziehung ist auch jenes der politischen Realisierbarkeit einer eigenen gesellschaftlichen Vision und damit des argentinischen Nationenbildungsprozesses. Nicht umsonst trägt Amalia das Witwenkleid: Ihre profunde Melancholie, ihre melancholische Blässe ist mehr als gerechtfertigt. Denn es bleibt kein Platz für die Verwirklichung der Hoffnungen und Träume einer Jugend, die vom „mal du siècle“ gezeichnet ist und nur in Ausnahmegestalten wie Daniel Bello jene Energie, jene Kraft und Dynamik aufbringt, um zumindest zu versuchen, gegen das Deplatziert-Sein in Raum und Zeit anzukämpfen.

Argentinien, so Daniel Bello, soll Europa in Amerika sein: wie die schöne Tucumanerin mit kastanienbraunem Haar, so wie die schöne Florencia Dupasquier, deren Namen ihre europäische Herkunft verrät. In dieser Vision haben indigene und schwarze Bevölkerung keinen Platz. Blickt man auf derartige Formulierungen, so beginnt man etwas zu begreifen von der tiefen Sehnsucht nach europäischer Erfüllung, von einer Phantasmagorie, die letztlich nur das Gefühl hundertjähriger Einsamkeit zurücklässt, ein Gefühl des Verwaist-Seins. Daher

21 Ebda., S. 183: „La asociación en todo y siempre para ser fuertes, para ser poderosos, para ser europeos en América.“ 
sollen die Bevölkerungsprobleme auch durch massive Einwanderung europäischer Migranten nach Argentinien gelöst werden: „Gobernar es poblar“ - aber nicht mit jedermann, sondern mit Einwanderern aus Europa!

Erinnert sei hier nochmals an die Faszinationskraft gerade jener Stadt, die Walter Benjamin als Hauptstadt des 19. Jahrhunderts bezeichnete und die Echeverría - der davon ein Lied zu singen wusste - wie folgt in seiner Peregrinación de Don Juan rühmte: „Paris war als Haupt, als Kapitale von Frankreich / ein immenser Lichtstern der im weiten Bereich / Licht den Völkern beider Welten spendet / und fruchtbare Strahlen, was niemals endet.“22 In kaum einem anderen Land Lateinamerikas war die Bewunderung für die französische Hauptstadt so grenzenlos wie in Argentinien.

Die Beziehung zwischen „Patria“ und Amalia als einander überlagernde Liebesbeziehung wird im Roman explizit thematisiert. Daniel Bello wirft seinem Freund vor, er spreche die ganze Zeit von der Patria, denke aber nur an Amalia; er wolle das Vaterland erobern, denke aber nur an die Eroberung seiner Geliebten. ${ }^{23}$ Vaterland und geliebte Frau werden für die Leserschaft erkennbar miteinander korreliert. Die „göttliche Amalia“ - wie sie im Roman des Öfteren im Unterschied zu Bellos Freundin, die (angesichts des Nachnamens ihres Freundes etwas doppeldeutig) nur „bellísima“ ist, genannt wird - ist nichts anderes als die Allegorie Argentiniens.

Dies ist eine Art nationaler Allegorese, die sich im Übrigen bis in unsere Zeit immer wieder findet. Denken Sie etwa an das Musical Evita - und die darauf basierenden Identifikationsströme - oder an eine Art Tango-Oper, deren Titelheldin María Astor Piazzollas „Opera Tango“ María de Buenos Aires eine neue (oder vielleicht doch nicht ganz so neue) Variante abgewinnt! Im aktuellen Kontext ist die Allegorie Argentiniens nicht mehr die Frau als Heilige, sondern als Hure, als Prostituierte. Die Grenze zwischen beiden Figurationen der Frau ist prekär und zerbrechlich: Beide entspringen einer paternalistischen, patriarchalischen Gesellschaft. Die dabei stattfindende Identifikation mit der Stadt - die im Spanischen ja bekanntlich weiblich ist (,la ciudad“) ist im Übrigen gleichgeblieben. Wo in der Vorlesung einige Ausschnitte aus Astor Piazzollas Opera Tango zu hören waren, können Sie sich bei der Lektüre, wenn Sie mögen, „Marías Antwort aus dem Jenseits“ im weltweiten Gewebe anhören! Im Schluss-Halleluja dieser modernen

22 Zitiert nach Leonor Flemings Einführung in Echeverría, Esteban: El Matadero. La Cautiva. Edición de Leonor Fleming. Madrid: Ediciones Cátedra 1986, S. 30: „Era París, cabeza de la Francia, / astro inmenso de luz que a la distancia / sobre los pueblos de uno y otro mundo / derrama sin cesar rayo fecundo ...“

23 Mármol, José: Amalia, S. 188. 
Oper erkennt der Chor, dass die verstorbene Maria ein Kind hinterlassen hat und sucht einen Namen für das Mädchen: Es wird selbstverständlich wieder María heißen. Beginnt damit der Teufelskreis Marías (und damit Argentiniens) von neuem? Es steht zu vermuten.

Dem mit der Romanliteratur des 19. Jahrhunderts vertrauten Leser wird das Ende von Villaverdes Cecilia Valdés einfallen, wo die schöne kubanische Mulattin, die Personifizierung der Zuckerrohrinsel am Ende des Romans eine Tochter hinterlässt, die ebenfalls verspricht, zu einer schönen Mulattin zu werden - ganz so, wie dies schon Cecilias wahnsinnig gewordene Mutter war. Die entsetzlich traurigen und tragischen Liebesbeziehungen und Liebesverhältnisse, in welchen den Frauen Rollen nationaler Allegorien im Blick der Männer unterschoben werden, ${ }^{24}$ scheinen sich bis in unsere Tage - und darüber hinaus - zu perpetuieren. María, Cecilia, Amalia: Sie zeigen Wandlungen weiblicher Identifikationsangebote nationaler Allegoresen, verharren aber doch immer innerhalb derselben Tradition einer Ästhetisierung und Literarisierung genderspezifisch übersetzter, gescheiterter Nationenbildungsprozesse, gleichviel, ob es sich um Heilige, Huren oder „Femmes fatales“ handelt. Sie sind allesamt schön und verführerisch, aber zugleich eben auch todbringend!

Auch Amalia ist übrigens eine Femme fatale, wenn auch eine wider Willen: Als sich Eduardo und Amalia gegenseitig ihre Liebe gestehen, bittet die schöne Tucumanerin ihren Geliebten, sich ihr letztlich lieber nicht zu nähern, da sie eines Tages auch ihm Unglück bringen werde. ${ }^{25}$ Amalias schwarzes Kleid gibt ihrer Liebe gleichsam eine tödliche Einfärbung, so strahlend weiß ihr Körper auch immer erscheinen mag. Der erste Kuss, der diesen letalen Liebesbund, welcher noch durch die Übergabe einer weißen Rose unterstrichen wird, ebenso emotional wie erotisch besiegelt, kann all dies ebenso wenig aufhalten wie das schreckliche Ende, das Liebende und Leser erst etliche hundert Seiten später erlöst. Denn selbstverständlich handelt es sich um einen jener zahlreichen romantischen Romane, deren zentraler Handlungsstrang nur über ihre Leiche verläuft. ${ }^{26}$

Der sich anschließende dritte Teil des Romans spielt zu Beginn in Montevideo und erweitert damit die Romandiegese um jene Dimension des Exils, in welcher sich Mármols Schreiben selbst zum Zeitpunkt der Abfassung seiner Narration

24 Vgl. hierzu Sommer, Doris: Foundational Fictions. The National Romances of Latin America. Berkeley: University of California Press 1991.

25 Mármol, José: Amalia, S. 206.

26 Vgl. Bronfen, Elisabeth: Nur über ihre Leiche. Tod, Weiblichkeit und Ästhetik. München: Deutscher Taschenbuch Verlag 1994; sowie (dies., Hg.): Die schöne Leiche. Weibliche Todesbilder in der Moderne. Wien: Goldmann 1992. 
ansiedelte. Montevideo ist - ganz wie schon bei Sarmiento angelegt - das Kontrastbild zu Buenos Aires und ist es in gewisser Weise bis heute geblieben. Die Hauptstadt Uruguays ist nicht allein Zentrum des Widerstands argentinischer Exilanten gegen die Rosas-Diktatur, sie ist auch eine für Europa und die Europäer, vor allem für die Franzosen offene Stadt, die in den Warenaustausch der Weltwirtschaft und in die weltumspannende Zirkulation der Ideen einbezogen ist. Als Daniel Bello im Hafen von Montevideo eintrifft, glaubt er freilich noch an die Stärke durch Einheit im argentinischen Exil; eine Vorstellung, die sich freilich bald schon als Illusion erweisen wird. ${ }^{27}$ Seine Weltsicht ist wohl zu sehr von Idealen geprägt!

Dieser Besuch erlaubt es dem Erzähler, die Welt der Proscriptos - eine eigene, isolierte, größtenteils abgeschlossene Welt, die ihre eigenen Mythen schafft und an diese trotzig glaubt - zu porträtieren sowie die Gegensätze zwischen den alten Unitariern und der jungen rebellischen Generation von Exilanten hervortreten zu lassen. Der argentinische Literat und Poet Florencio Varela, eine historische Gestalt, zeigt die Problematik des Exils für die Intellektuellen und vor allem die Schriftsteller auf, nimmt gerade er doch eine Zwischenstellung ein zwischen der alten Literatengeneration der „Neoclásicos“ und den neuen argentinischen Romantikern, die wie Esteban Echeverría ebenfalls nun ihre zweite Heimat in Uruguay gefunden haben. Schnell muss Bello erfahren, dass seine unitarischen Gesprächspartner in einer anderen Welt leben und an neuen Informationen aus Argentinien gar nicht interessiert sind, könnte all dies doch ihre Vorstellungen, mehr aber noch ihre Vorherrschaft im Exil gefährden. José Mármol analysiert in diesen Szenen mit feinem Gespür jene Verwerfungen, welche durch die Existenz und die Bedingungen eines langen Exils entstehen.

Entscheidend ist in diesem Zusammenhang eine Szene im Roman, in welcher Varela die Meldung vom Sieg der Rosas-Truppen in Sauce Grande einer geradezu textkritischen Lektüre unterzieht, um damit ausgehend von bestimmten Repräsentationsformen dieser journalistisch-propagandistischen Prosa die Tatsache des Sieges selbst zu leugnen. Man will es ganz einfach nicht wahrhaben, dass der Gegner militärisch gesiegt haben könnte und baut sich folglich eine andere Wahrheit, die - entschuldigen Sie bitte! - auf ,alternativen Fakten' beruht. ${ }^{28}$ Parallel hierzu macht der Erzählerdiskurs klar, dass es sich bei Daniel Bello nicht mehr um einen Unitarier im Sinne eines Parteigängers alten Typs handelt: Er repräsentiert vielmehr die junge Generation, die den alten Unitariern durchaus verdächtig und unzuverlässig erscheint, stellen sie doch implizit die Vorherrschaft der Alt-

27 Mármol, José: Amalia, S. 209 f.

28 Ebda., S. $223 \mathrm{f}$. 
gedienten in Frage. Mit anderen Worten: Die Gespräche Bellos in Montevideo verlaufen mehr als enttäuschend, und so überrascht es nicht, dass düstere Vorahnungen sich seiner Seele bemächtigen und er sich der Vision bewusst wird, die folgenden Auseinandersetzungen mit Rosas nicht mehr lebendig überstehen zu können. Das tragische Geschehen spitzt sich langsam auch auf der historischen, soziopolitischen und militärischen Ebene des Romans zu.

Selbst die unglaubliche Energie Daniel Bellos wird zunehmend vom düsteren Flügelschlag melancholischer Lethargie erfasst, wenn auch längst noch nicht gelähmt. Das Romangeschehen dunkelt sich zusehends ein und die Melancholie überwuchert immer weitere Bereiche der Diegese. Kontrastiv zu dieser allgemeinen inneren Gemütsverfassung wird das Porträt Montevideos eingefügt; einer Stadt, in welcher das Geld mit vollen Händen ausgegeben wird und die sich auf dem Höhepunkt ihrer damaligen Entwicklung befindet. Eine Szene im Kaffeehaus schließt sich an, in das die historischen Gestalten von Alberdi, Gutiérrez, Irigoyen und Echeverría eintreten. ${ }^{29}$ José Mármol lässt ein lebendiges Bild der verschiedenen Generationen im uruguayischen Exil entstehen, das er aus eigener Anschauung bestens kannte.

Das vierte Kapitel des dritten Teils schließt den Aufenthalt Bellos in Montevideo ab und präsentiert eine lyrische Meditation des jungen Helden auf dem Meer. Wir befinden uns auf der Rückfahrt über den Río de la Plata, der mit Hilfe eines Schmugglers klammheimlich in Richtung Argentinien überquert wird. Dem schönen Bello ist die Zerrissenheit des argentinischen Exils - und damit seine eigene politische Schwäche - klar geworden; er weiß nun, dass es auch im uruguayischen Exil Führer mit absolutem Machtanspruch gibt, auch wenn diese nicht so blutrünstig wie Rosas seien. ${ }^{30}$ Von politischer Einheit sind die Gegner der Rosas-Diktatur 1840 noch weit entfernt. Der langen Liste erlittener Enttäuschungen folgt die Einsicht, dass man den Menschen nicht mehr allzu sehr vertrauen dürfe, sondern vielmehr auf Gott bauen müsse. Daniel Bellos Blick geht bei dieser nächtlichen Meditation auf dem Schiff nach oben, zum Firmament, wo er nach Trost und Sicherheit sucht. Doch noch geben die Sterne keine endgültige Auskunft ...

Auf die poetische Meditation folgt die krude Präsentation der Gewaltherrschaft mit einem Porträt der fanatischen Doña María Josefa Ezcurra. Erneut haben wir es mit einer Kontrasttechnik zu tun, die den himmlischen Sternen die teuflische Unterwelt der in Buenos Aires Herrschenden entgegensetzt. Josefa, die Schwiegermutter von Rosas, ist dem verwundeten Eduardo Belgrano bereits

29 Ebda., S. 231.

30 Ebda., S. 234. 
auf die Spur gekommen und vermutet ihn mit guten Gründen in Amalias Landhaus. Der Erzähler verwendet einige Sorgfalt darauf, die fanatische Frau mit dem Teufel zu assoziieren, der ihr buchstäblich diese Vermutung in den Kopf gesetzt zu haben scheint. Der Kreis der Hölle schließt sich um das himmlische Geschöpf Amalia und ihren Verehrer. Auch in diesem Kampf gegen die Mächte der Finsternis ist Amalia implizit die Verkörperung Argentiniens: Noch immer hoffen und bangen die Leserinnen und Leser mit ihr und ihrer Liebe.

Doch das Unheil nähert sich mit Riesenschritten! Eine junge schwarze Dienerin Amalias - und der implizite Rassismus ist unübersehbar - schwärzt ihre weiße Herrin an: Sie dient María Josefa als Spionin. All dies ist sehr gut vergleichbar mit Domingo Faustino Sarmientos Facundo, wo die Schwarzen als Gefahr für die unitarischen, rechtschaffenen weißen Bürger erschienen waren und deren wohlbegründete Ordnung gefährdet hatten. Die Macht der Verfolger wird größer, jene der Verfolgten stetig kleiner: Daniel Bellos Mitstreiter in der zu gründenden Assoziation sind von knapp dreißig auf ganze sieben zusammengeschmolzen, die Reihen der Kämpfer gegen die Rosas-Diktatur lichten sich.

So stark ist innerhalb kurzer Zeit der Aderlass, dass immer größere Teile der jungen Argentinier ins Exil getrieben werden, wodurch den ehrgeizigen Plänen Bellos, den Diktator von Buenos Aires zu bekämpfen und möglichst zu stürzen, der Boden entzogen wird. Unterdessen übt sich das Liebespaar in geistig-intellektueller Harmonie: Es sind verwandte Seelen, die in romantischer Liebe zueinander finden; und das geht nicht ohne gemeinsame Lektüre ab. Eduardo übersetzt seiner Amalia die schönsten Stellen des Manfredo von Lord Byron. ${ }^{31}$ Die beiden Liebenden vergessen die Außenwelt und sind ganz in ihrer Welt romantischer Emotionen im Leben und Lesen gefangen. Gerne möchte ich Ihnen diese Szene einmal vorführen:

Es war fünf Uhr an einem kalten und nebligen Nachmittag, und Eduardo saß neben dem Kamin auf einem kleinen Schemel zu Füßen von Amalia. Er übersetzte ihr eine der schönsten Passagen des Manfred von Lord Byron; und Amalia stützte ihren Arm auf die Schulter Eduardos, wobei ihre Locken aus Seide leicht ihre hohe und bleiche Stirne streiften. Und sie hörte ihn, sich selbst entfremdet, mehr durch seine Stimme, die zu ihrem Herzen drang, als durch die schönen Kunstgriffe der Einbildungskraft des Dichters hindurch; von Zeit zu Zeit hob Eduardo seinen Kopf und suchte in den Augen seiner Amalia eine noch größere Flut an Poesie, als ihn die Gedanken des Adlers unter den Poeten des 19. Jahrhunderts verströmten.

Sie und er repräsentierten dort das lebendige und vollkommene Gemälde vollständigen Glückes [...]. ${ }^{32}$

31 Ebda., S. 253.

32 Ebda. 
Dies ist die Szene eines Interieur, das vollständige Geborgenheit, wunschloses Glück und intelligente Beschäftigung ausstrahlt. Das flackernde Kaminfeuer versetzt uns geradezu in eine Atmosphäre und ein Klima, wie wir es in England empfinden könnten. Und in der Tat sind wir auch nicht weit von einem derartigen Ambiente entfernt. Überdies haben wir es mit einer Szene zu tun, die topisch Leben, Lesen und Lieben eng führt: Die gemeinsame Lektüre hatte nicht umsonst Paolo und Francesca zusammengebracht, bis sich ihre Münder nicht mehr voneinander lösen konnten. ${ }^{33}$ José Mármol greift an dieser Stelle tief in die Kiste langer europäischer Literaturtraditionen und entfaltet transatlantische Bezugnahmen, deren Intertextualität jedoch zweifellos - und nicht allein wegen Lord Byron - englisch eingefärbt sind. Tatsächlich könnte diese Lese- und Liebesszene auch vollständig in einem windumtosten englischen Landhaus stattgefunden haben.

In dieser vertrauten Szenerie ist es die Stimme des Mannes, die tief in den Körper der jungen Frau eindringt und die bleiche romantische Heldin stark bewegt. Allerdings gibt es eine Veränderung oder Mutation dieser Szenerie, die keineswegs zufälliger Natur ist: In dieser Passage wird Lord Byron, jener Dichter der englischen Romantik, der hier gleichsam aus gewachsener historischer Distanz zu den großen Dichterfürsten des 19. Jahrhunderts gerechnet wird, nicht gemeinsam und eng umschlungen gelesen. Er wird vielmehr ins Spanische übersetzt, wird mithin einer Übersetzungsarbeit unterzogen, die sich im transatlantischen Zwischenraum zwischen beiden Welten bewegt. Im selben Atemzug setzt Byron von England nach Argentinien über, so dass eine doppelte Übersetzungsübung entsteht, die einmal mehr die Asymmetrie und zugleich die Wichtigkeit des Übersetzens, also die Verbindung des Transnationalen mit dem Translationalen unterstreicht. Das Übersetzen wird mit dem Übersetzen gekoppelt und umschreibt eine Intertextualität, welche wie eine Nabelschnur die asymmetrische Abhängigkeit der argentinischen Literatur von der europäischen im 19. Jahrhundert anzeigt. ${ }^{34}$

Doch das Netz, das Doña María Josefa um die Unitarier zieht, wird immer enger: Sie hat sich bei einem unangemeldeten Überraschungsbesuch im Hause Amalias persönlich von der Anwesenheit eines jungen Mannes überzeugt, der zudem aufgrund seiner Verwundung noch aufschreit, als sie sich absichtlich auf seinem linken Oberschenkel abstützt. Der Beweis also ist erbracht und das

$33 \mathrm{Zu}$ Dantes Paolo und Francesca und die langfristige Wirkung dieser Konfiguration auf die Darstellung von Liebe im Abendland vgl. Ette, Ottmar: LiebeLesen, S. 7 ff., 56 f. u. 532 ff. Bereits das Cover dieser Buchausgabe bezieht sich auf eine romantische Lesart dieser berühmten Liebesszene aus Dantes Commedia.

34 Zu einer komplementären Deutung vgl. Ette: LiebeLesen, S. 517-519. 
Liebespaar verraten! Das Verderben nimmt seinen Lauf, wenn es auch durch allerlei retardierende Einschübe und Unterbrechungen immer wieder hinausgeschoben wird. Noch scheitert auf Grund der beherzten Reaktionsschnelligkeit Daniel Bellos, der Eduardo aus dem Hause Amalias entfernt, ein erster Versuch der Mazorca, der Schergen der Rosas-Diktatur, den jungen Belgrano im Hause Amalias gefangen zu nehmen. Doch das Netz um die Liebenden, aber auch um Daniel Bello zieht sich spürbar zu.

So wird die Liebesgeschichte nun wieder stärker in den Kontext historischer Aktionen gerückt, unterstützt von eingebauten Dokumenten, die vom Vorrücken der Truppen Lavalles auf Buenos Aires sprechen und den Unitariern wieder neuen Mut und neue Hoffnung einflößen. Auch diese historische Kontextualisierung besitzt selbstverständlich eine retardierende Funktion, verstärkt aber gleichzeitig die Möglichkeiten des Romans, nicht allein historisches Geschehen, sondern dessen konkretes Erleben und das Lebenswissen der einzelnen Figuren zur Geltung zu bringen. In diesem Zusammenhang zeigt der Roman, dass er einer abstrakten Geschichtsschreibung dadurch überlegen ist, insofern er nicht die schlichte Faktizität der Wirklichkeit, sondern erlebbare und erlebte Wirklichkeiten in den ästhetischen Mittelpunkt rückt. Aus Sicht der romanesken Figuren ist die Zukunft noch offen: Sie können sich in dieser Geschichte so, aber auch ganz anders entscheiden.

Beständig pendelt der Text zwischen romantischem Liebesroman, politischem Thriller und historischem Roman, wobei sich alle drei Pole wechselseitig beeinflussen und in ihrer Wirkung stabilisieren. Immer wieder wird die entscheidende Wendung hinausgezögert - auch dies ein Teil jener Strategien, die sich insbesondere der Feuilletonroman des 19. Jahrhunderts durch sein periodisches Erscheinen in der Zeitung erarbeitete. Das geschätzte Lesepublikum wird durch ständige Querverweise, Handlungsveränderungen und retardierende Einschübe bei der Stange gehalten. Denn vergessen wir nicht: Unser historischer Roman Amalia ist zugleich ein Feuilletonroman, der erstmals in einem politisch eindeutig orientierten Periodikum erschien, als Waffe im politischen Kampf des Exils gegen eine verhasste Diktatur!

Vor diesem Hintergrund ist Amalia, in gewisser Weise vergleichbar mit Fernández de Lizardis Periquillo Sarniento, die Fortsetzung des politischen Kampfes des Journalisten mit literarischen Mitteln gegen einen Feind, der noch immer übermächtig ist. Auf Ebene der Tragödie - und auch auf sie bezieht sich der Roman Mármols explizit - entspräche dieser Feuilletontechnik der Verschiebung und Verzögerung die Technik des „retardissement“, eine Retardierung, die dem Publikum, also der Leserschaft noch ein wenig Zeit zum Atemholen lässt, bevor die Schlusskatastrophe über alles hereinbricht. José Mármol gestaltet diesen „Suspense“ sehr großzügig und lässt seiner Leserschaft viel Zeit zum Atemschöpfen. 
Dies birgt Gefahren: Denn zumindest das heutige Lesepublikum läuft bisweilen Gefahr, angesichts der unübersehbaren Längen des Romans nicht Atem zu holen, sondern im schlimmsten Falle einzuschlafen.

Auch Juan Manuel de Rosas zeigt angesichts der heranrückenden Truppen von General Lavalle Nerven. Daran ändert auch nichts die gute argentinische Küche einer Mulattin, die dem Diktator immer wieder schmackhafte Fleischgerichte auftischt, welche in offenem Kontrast zur verfeinerten französischen Küche stehen. Der uns bereits bekannte Alejo Carpentier hat hier offenkundig gut aufgepasst und einige Textelemente, insbesondere die Mulattin, in seinen eigenen Diktatorenroman El recurso del método intertextuell übernommen. Jedenfalls hat Juan Manuel de Rosas deutlich vor einer Niederlage gegen die unitarischen Truppen Angst und bereitet alles für seine rasche Flucht ins Exil vor. Diese sollte über die britische Botschaft abgewickelt werden; ganz so, wie Rosas im Jahre 1852 - also zwölf Jahre nach den Ereignissen unseres Romans - dann tatsächlich ins englische Exil gelangen sollte.

Doch die Rosas-Diktatur funktionierte noch 1840 in Argentinien weiter und baute ihr repressives Staatssystem aus. Der recht zurückhaltende Polizeichef von Rosas, Victorica, der María Josefa Ezcurra eher ein Dorn im Auge ist, sieht sich im Hause Amalias um, was im Übrigen zu einem wahren Farbenspiel Anlass gibt. Denn Victorica erblickt zu seinem Missfallen überall im Interieur der Quinta Amalias die Farben Blau und Weiß - nicht die Farben der Federales. Amalia ihrerseits wird vor lauter Wut im Gesicht ganz rot, „punzó“, was beim mitgekommenen Opportunisten Mariño dazu führt, seinerseits im Gesicht ganz bleich zu werden. Dies ist nicht nur eine Verwirrung der Gefühle, sondern vor allem eine Verwirrung politischer Farben und ihrer Symbolik.

Der inquisitorische Besuch Victoricas bietet freilich im Roman vor allem den willkommenen Anlass, eine mit „Mármol“ unterschriebene Fußnote einzufügen, die auf die eigenartige Bekanntschaft des jungen Literaten mit Rosas’ Polizeichef hinweist. Ich darf diese autobiographische Fußnote kurz anführen:

Als ich 1839 im Gefängnis und in den Ketten von Rosas die staatsbürgerliche Taufe erhielt, die er allen Argentiniern zugedachte, die sich weigerten, sich in jenem Pfuhl an Blut und Lastern zu prostituieren, in welchem sich seine Freunde suhlten, da erwies mir Don Bernardo Victorica gewisse Aufmerksamkeiten, die absolut verboten waren.

Allein und in einen Kerker geworfen, wohin kaum das Tageslicht durch eine kleine Luke drang, werde ich niemals die Freude vergessen, die ich empfand, als der Chef der Polizei mir die Erlaubnis gab, einige Kerzen und Bücher herbeizuholen. Und in der Flamme dieser Kerzen schwärzte ich einige Mate-Stengel, um mit ihnen auf die Wände meines Kerkers die ersten Verse gegen Rosas und die ersten Schwüre meiner Seele von neunzehn Jahren zu schreiben, alles gegen den Tyrannen und für die Freiheit meines Vaterlandes zu tun, was 
ich dann auch getan habe und während der langen Periode meines Exils auch weiterhin tun werde. - MARMOL ${ }^{35}$

Erneut wird in dieser Anmerkung, wie schon in der dem gesamten Roman vorangestellten „Explicación“, ein paratextuelles Element hinzugefügt, um zum einen die historische Fundierung und Glaubwürdigkeit des Erzählten, vor allem aber die autobiographisch verankerte Dimension des Schreibens herauszustellen. Das Schreiben des Romans geht letztlich zurück auf jenes im Gefängnis: Es ist gleichsam dessen Verlängerung. Dieses Schreiben im Gefängnis verweist wiederum auf das Schreiben von Sarmiento an jene Wand in Argentinien, die er den Interpretationsversuchen seiner Häscher überlassen musste, als er sich ins Exil nach Chile absetzte: „On ne tue point les idées.“

Auch in diesem Falle - und wieder kommt uns in dieser Vorlesung Fernández de Lizardis El Periquillo Sarniento in den Sinn - handelt es sich um ein verortetes Schreiben, die Berufung auf ein Gedicht, das José Mármol im Übrigen nach seiner Flucht ins Exil unter dem Titel A Rosas veröffentlichte. Amalia ist letztlich nur die Fortsetzung einer solchen verorteten ,écriture“ mit den Mitteln des Romans. Schreiben wird zum Aufschrei gegen die Rosas-Diktatur: Schrei und Schreiben stehen in unmittelbarem Zusammenhang.

DieSchrift der Feder weist den Weg zurück zu ihrer Herkunft, ihrem Ursprungsmoment in Argentinien, geschrieben mit argentinischem Mate an die Wände eines argentinischen Gefängnisses. Wieder ist es der amerikanische „calabozo“, von dem Lezama Lima mit Blick auf Fray Servando Teresa de Mier sprach, wieder ist es der Kerker, in welchem sich die Schrift ihren Weg sucht und fruchtbar wird. Das Schreiben im Gefängnis wird zu einem Schrei aus dem Gefängnis, welcher dem Schreiben nach dem Gefängnis seine volle und ganze Legitimität verleiht. So haben wir es mit einer Gefängnisliteratur zu tun, die sich im Roman paratextuell ihr Schattendasein er-schreibt und verteidigt, ja mehr noch: ihre ganze Würde als Schrift und Schreiben von Literatur aus dieser Verfolgung bezieht. Als die Verfolgung aufhörte, als der Aufschrei ausbleiben konnte, versiegte bei José Mármol die Feder und das Schreiben kam an ein Ende.

Zugleich sind diese historischen Vorgänge aus dem Jahre 1839 - der junge José Mármol befand sich für die eher kurze Zeitdauer vom ersten bis zum siebten April jenes Jahres im Gefängnis - unmittelbar jenen vorgeschaltet, von denen der Roman berichtet. Dessen erzählte Zeit situiert sich zwischen 1839 und 1851, zwischen dem Gefängnis in Buenos Aires und dem Exil in Montevideo, wobei der Fokus der zeitlichen Diegese auf dem Jahr 1840 liegt. Es sei an dieser Stelle ein-

35 Mármol, José: Amalia, S. 291. 
gefügt, dass eine Fußnote ${ }^{36}$ eine doppelte Zeit der Niederschrift angibt, nämlich zum einen das Jahr 1851 in Montevideo und zum zweiten den Zeitraum nach Durchsicht einer Vielzahl von Dokumenten, die in Buenos Aires nach dem Ende der Rosas-Diktatur in die Buchfassung aufgenommen wurden.

Durch den zunehmenden Einbau historischer Dokumente versuchte der Autor darüber hinaus, dem historischen Charakter seines Romans einen zusätzlichen, gleichsam testimonialen Akzent zu vermitteln. Die vom Text konstruierte Autorfigur wird zum Zeugen, ja Blutzeugen all jener Ereignisse, die Mármol in romanesker Form niederschrieb. Der Roman tritt hier erkennbar an die Stelle einer Geschichtsschreibung, die erst lange nach 1852 eine neue offizielle Geschichte Argentiniens ausarbeiten wird. Es sollte die Geschichte der Sieger sein. Die historischen Tatsachen, so erläutert der Erzählerdiskurs, ${ }^{37}$ müssten im (fiktionalen) Roman dargestellt werden, damit der Roman aus den dargestellten Ereignissen die philosophischen Konsequenzen ziehen könne. Der politische und historische Roman von José Mármol erhebt mithin nicht nur einen mimetischen und historiographischen, sondern auch einen geschichtsphilosophischen Anspruch; auch dies ein Ergebnis jener „ficción calculada“, die der Autor im Vorwort ankündigt und im Verlauf seines Romans auf die Leserschaft einwirken lässt.

Es häufen sich in der Folge die langen Einschübe des Erzählerdiskurses, der die argentinische Geschichte beleuchtet und alles Schändliche und Schreckliche auf Seiten der Federales ansiedelt - ohne Facundo Quiroga zu vergessen, der sogar seine eigene Heimatstadt in Flammen habe aufgehen lassen. ${ }^{38}$ Es erscheinen all jene Caudillos, die schon in Sarmientos Facundo als "Gauchos malos“ gebrandmarkt worden waren, wobei sie alle zum Höhepunkt der Rosas-Diktatur hinführen. Der Erzählerdiskurs geht in Amalia in derartigen Passagen immer stärker in einen parteipolitisch-propagandistischen Diskurs über, dem eine klar manichäische, antithetische Struktur zugrunde liegt. So erfolgen immer wieder auch Abrechnungen parteipolitischer Art: Mit Ausnahme der Jesuiten habe der Klerus versagt, habe er sich doch vollständig prosterniert und Rosas ergeben. Demgegenüber erhebt der Erzähler ein Loblied auf das Christentum, das mit Christoph Kolumbus in die Neue Welt gekommen sei: ${ }^{39}$ Mármol greift in diesem Zusammenhang zweifellos zurück auf die vorwiegend ästhetisch ausgerichtete Eloge alles Christlichen in Chateaubriands Le Génie du Christianisme, das in der Romantik in beiden Welten seine volle Kraft entfaltete.

36 Ebda., S. 421.

37 Ebda., S. 313.

38 Ebda., S. 337.

39 Ebda., S. 340. 
Auch die Gauchos und ihre Lebensart, die so sehr jener der Städter entgegensteht, die aber doch im Grunde das argentinische Volk verkörperten, darf in diesem so argentinisch gewollten Roman nicht fehlen. ${ }^{40}$ Die weltpolitischgeschichtsphilosophischen Reflexionen setzen wenig später ausgehend von den Überlegungen zur Sklaverei Amerikas ein, die bereits mit dem Augenblick der Entdeckung begonnen habe. ${ }^{41}$ Selbst die Befreiung, die Independencia habe sich an Europa, an der französischen Revolution ausgerichtet. Das Zusammentreten der französischen Generalstände, das Zustandekommen der Französischen Revolution, die Zerfallserscheinungen und politischen Ereignisse in Spanien, der Einmarsch der Franzosen in Spanien und der Beginn des hispanoamerikanischen Befreiungskampfes werden vom Erzähler in eine direkte Kausalkette gebracht. ${ }^{42}$

Vor allem aber seien Flugschriften und Bücher aus Frankreich nach Amerika gelangt: Die Macht des Wortes und der Schrift ist für den Erzähler letztlich entscheidend für die fundamentalen revolutionären Ereignisse auf dem amerikanischen Kontinent. Anlässlich der hispanoamerikanischen Independencia kommt der Erzähler nicht umhin, Buenos Aires jene Rolle zuzuschreiben, welche Gott in der Schöpfung spiele: ${ }^{43}$ eine ,dezente‘, ,schüchterne‘ Zurückhaltung, wie sie den Einwohnern der Stadt, den „Porteños“ stets eigen war. Der geschichtsphilosophische Erzählerdiskurs beharrt ein ums andere Mal auf der Vorstellung vom Ideentransport von der französischen zur amerikanischen (sprich: hispanoamerikanischen) Seite des Atlantik: Dies sei die Initiation für die Suche nach Freiheit gewesen. Das große Problem habe aber darin bestanden, freiheitliche Vorstellungen dort zu verbreiten, wo alle Geister von monarchistischen und autoritären Gewaltstrukturen beherrscht gewesen seien. Immer häufigere Aufstände gegen die „clase ilustrada“ der Städte seien die notwendige Folge dieses Zustands gewesen. ${ }^{44}$

Ähnlich wie bei Domingo Faustino Sarmiento erscheint all dies als ein langer Kampf gegen das „principio civilizador“ innerhalb der noch unfertigen Gesellschaften. So sei die koloniale Tradition gegen das revolutionäre Bewusstsein aufgestanden und habe die Macht ergriffen. Daraus leitet der Erzähler seine Kritik an der Utopie der Independencia ab, die davon ausgegangen sei, dass man die hehren Vorstellungen einfach auf die Länder Amerikas übertragen könne. Doch dies sei niemals der Fall gewesen: Denn die Barbarei habe sich in einem einzigen

40 Ebda., S. 350 ff.

41 Ebda., S. 352.

42 Ebda., S. 352.

43 Ebda., S. 353.

44 Ebda., S. 354. 
Manne verkörpert, Juan Manuel de Rosas, der in jeglicher Hinsicht der beste Gaucho gewesen sei. ${ }^{45}$ Rosas habe letzterem den Vorrang eingeräumt, und so stünden sich nun Zivilisation und Barbarei in ihrem Kampfe gegenüber.

Sie sehen einmal mehr, wie homogen die politisch-kulturellen Vorstellungen der Argentinier waren, die im Exil die Feder ergriffen! Sie wird den ehernen Kernbestand der künftigen offiziellen Geschichtsschreibung Argentiniens bilden. Die Rollen sind damit für die militärische Entscheidungsschlacht zwischen Rosas und Lavalle gut verteilt: Es ist der ewige Kampf zwischen dem Guten und dem Bösen, zwischen Zivilisation und Barbarei, zwischen Freiheit und Unfreiheit, zwischen Recht und Gewalt. Gerade am Beispiel einer Schlacht, in welcher sich stets alles zu Freund oder zu Feind anordnet, lassen sich derartige Manichäismen leicht vorführen. Genau darin liegt das Verführerische dieses Diskurses, und in dieser einfachen Gegenüberstellung lag auch die langanhaltende Wirkung derartiger Passagen. Die Kämpfer der Freiheit treten den Heeren der Sklaven entgegen - und sie werden zunächst noch verlieren. Noch weiß der Leser, noch weiß die Leserin nicht - soweit sie es nicht aus der Geschichte wissen -, dass Lavalle der Schlacht aus dem Wege gehen und damit Rosas stark machen wird. Die Barbarei wird fürs Erste obsiegen: Die Würfel sind gefallen!

Die Schlacht auf dem Schlachtfeld ist bald entschieden, wenn sie auch romantechnisch in der Schwebe gehalten wird. Noch bliebe Zeit für die Flucht Daniel Bellos und der Liebenden ins rettende Exil. Doch kommt es nur zu einer romantischen Liebesszene, die ich Ihnen zur Erbauung ans Herz legen möchte:

Du liebst mich, nicht wahr? Du akzeptierst mein Schicksal in dieser Welt, nicht wahr? Ja.

Welches auch immer es sein wird?

Ja, ja, welches auch immer es sein wird.

Du Engel meiner Seele!

Bist Du glücklich, so werde ich in Deinem Lächeln das unbeschreibliche Abenteuer der Engel trinken.

Amalia!

Bist Du dem Unheil verfallen, so werde ich Dein Leid teilen; und ...

... Und? Nun sag' schon.

Und wenn ein ungutes Schicksal, das Dich verfolgt, Dich zum Tode führte, so würde der Schlag, der Dein Leben abtrennt, meinen Geist auf der Suche nach Dir auffliegen lassen ... Eduardo drückte jene großzügige Kreatur an sein Herz; und in diesem Augenblick, als sie ihr letztes Wort gesprochen hatte, das ihr vom Schwung des Enthusiasmus, in dem sie sich befand, eingegeben worden war, ließ sich weit entfernt ein langer, dumpfer Donner hören, der im Raume vibrierte wie das Echo eines Kanonenschusses in gebirgigem Gelände.

45 Ebda., S. 355. 


\begin{abstract}
Der Aberglaube ist der unzertrennliche Begleiter der poetischen Geister, und jene beiden jungen Leute, die in diesem Moment so trunken von Glück waren, fassten sich an die Hände und schauten sich einige Sekunden lang mit einem undefinierbaren Gesichtsausdruck an. Schließlich senkte Amalia ihr Haupt, als wäre sie von einer prophetischen und grässlichen Idee ergriffen. [...]

Der Sturm ist weit weg, Amalia. Und unterdessen dient ein so reiner Himmel wie Deine Seele als Schleier über unsrer beider Stirne. Das Universum ist unser Tempel, und Gott ist der heilige Hohepriester, der die wohlempfundene Liebe unserer Seelen weiht, von jenen Wolken und von jenen Sternen herab; Gott selbst, der sie mit dem Magnetismus seines Blickes hält, und unter allen Sternen den unsrigen ..., ja ..., jener dort ..., jener dort muss der Stern unseres Glückes auf Erden sein ... Siehst Du ihn nicht? Hell wie Deine Seele, strahlend wie Deine Augen, hübsch und anmutig wie Du selbst ... Siehst Du ihn, meine Amalia? Nein ... Jener dort, antwortete die junge Frau, streckte ihren Arm aus und zeigte auf einen kleinen und schwach leuchtenden Stern, der nahe daran schien, in den Fluten des machtvollen, in diesem Augenblick wie die ganze Natur so stillen Río de la Plata zu versinken. ${ }^{46}$
\end{abstract}

Alles in der Natur ist ein Zeichen, das die Liebenden fast gegen ihren Willen zu lesen verstehen. Die Natur ist in dieser Passage und im negativen Sinne eine Korrespondenz-Natur, welche gleichsam als Protagonist mit einer eigenen Stimme auftritt. Und sie hat ihr Machtwort gesprochen, auch wenn noch einmal eine trügerische Ruhe eingekehrt ist. Das Universum ist nur scheinbar Tempel der Liebenden, in welchem Gottvater den Kult der Liebe gestattet - doch nicht mehr lange!

Nur scheinbar entspricht das Firmament Körper und Seele Amalias, nur scheinbar gelingt es Eduardo, auf harmonische Weise eine Beziehung zwischen Makrokosmos und Mikrokosmos herzustellen. Amalias Arm weist in Richtung des verglimmenden Sterns, in dessen Bewegung sich das Verlöschen des kalten Feuers im mächtigen Wasser des La Plata-Stromes andeutet - jenes Río de la Plata, der doch die Möglichkeit geboten hätte, sich ins sichere Exil zu retten. Die Liebenden versuchen ihr Schicksal in den Sternen zu lesen, doch ihre Lektüren stimmen nicht gänzlich überein: Denn Eduardo Belgrano versucht in den Sternen das zu lesen, was er sich erträumt, aber nicht das, was er dort erblickt.

Die Natur ist ruhig geworden, der Sturm scheint fern, das Gewitter zeigte sich nur kurz und ließ seinen dumpfen Donner vernehmen. Und doch ist in dieser Szene - die nichts außer Acht lässt, was zur Rezeptur romantischer Liebesszenen im Roman der ersten Hälfte des 19. Jahrhunderts gehörte - der verlöschende Stern ein beredtes Zeichen des Fatums, das über der Liebe zu Amalia und zugleich über der Liebe zur „Patria“ steht. Der Blick über den La Plata, der zu jener Reise einlädt, welche die Liebenden noch nicht antreten wollen, um sich in Montevideo

46 Ebda., S. $384 \mathrm{f}$. 
in Sicherheit zu bringen, ist nicht der Blick in eine leuchtende Zukunft in Freiheit: Es ist der Blick über den Styx, den mächtigen Todesstrom, dem nichts entrinnen kann. Die Liebenden ahnen es - und mit ihnen ihr Lesepublikum, das die Zeichen der Natur zu lesen gelernt hat.

Unter dem Messer der Mazorca und der Rosas-Schergen ist die Stadt zum „desierto“ geworden, sozusagen eine verkehrte Welt, in welcher nun die Großstadt die menschenleere Wüste bildet. ${ }^{47}$ Nicht einmal Rom in den schlimmsten Zeiten der Tyrannei sei mit dem heutigen Buenos Aires von 1840 vergleichbar. Buenos Aires, auf das sich die Romandiegese im Wesentlichen unter Einschluss einiger „Arrabales“ und Landhäuser konzentriert, ist die eigentliche Hauptdarstellerin des Romans, die wirkliche Hauptfigur, um deren nationale Gesundheit es geht. Und sie wird unter der Rosas-Diktatur geschändet: Der Roman strotzt nun vor Schilderungen der barbarischen, sadistischen Grausamkeiten unter Juan Manuel de Rosas. Auch in diesen Szenen wird das Messer erneut zum Protagonisten, der Diktator selbst zum bluttrinkenden Monster. Als er um ein Glas Wasser bittet und dieses trinkt, spiegelt sich darin die untergehende Sonne so, dass er infolge des optischen Effekts Blut in seine Kehle stürzt - das Blut seiner Opfer. ${ }^{48}$ Juan Manuel de Rosas steht ebenso wie Doña María Josefa Ezcurra mit dem Teufel im Bunde!

An seinem Ende spiegelt sich der ganze Roman in der historischen Tatsache des Abrückens der Truppen von General Lavalle aus Buenos Aires. Der UnitarierGeneral wagt sich nicht an die Eroberung der Stadt; und daher muss er auch scheitern, ist Buenos Aires doch die Hauptperson in der nationalen Tragödie, die José Mármol zur romanesken Aufführung bringt. Auf von Daniel Bello vorbereiteten Fluchtwegen gelangen die schöne Florencia Dupasquier und ihre Mutter mit Hilfe der Franzosen ins Exil nach Montevideo. Amalia jedoch fährt nicht mit: Sie will nicht mehr von der Seite Eduardos weichen, ganz so, wie sie es in der angeführten Passage kundgetan hatte. So wird die junge Frau, die Inkarnation der Schönheit Argentiniens gemeinsam mit ihrem Liebhaber untergehen.

Eduardo begleitet die Abfahrt des Schiffes - ähnlich wie bei Victor Hugo -mit den Worten „Fatalidad, fatalidad“: Damit ist das Urteil endgültig gesprochen! Im Río de la Plata wird Eduardos und Amalias Stern verlöschen, was die Ambivalenz dieses gewaltigen Wasserstreifens nochmals aufwertet. Denn für die einen bringt er die Rettung, für die anderen ist er Zeichen des Todes: Eduardo ist von den ersten Seiten des Romans an bemüht, den Fluss und Meeresarm zu überqueren, doch wird ihm dies lebendig nie gelingen.

47 Ebda., S. 413.

48 Ebda., S. 430. 
Aber der Roman hält für seine Leserinnen und Leser eine geschichtsphilosophische Tröstung bereit: All dies ist im Sinne Hegels aufgehoben, ist für die unumgängliche Nationenbildung geschichtlich notwendig. Denn die Independencia - ähnlich war dies auch in Sarmientos Facundo zum Ausdruck gebracht worden - ist noch nicht zu Ende, sie muss vielmehr erst noch zu Ende gebracht werden, ${ }^{49}$ obwohl die Gegenwart schwer auf dem Land wiegt. Der kommende Frühling im Roman markiert nicht einen neuen Aufbruch, sondern den Auftakt zu einem schrecklichen Blutbad; und doch scheint all dies nicht ohne einen geheimen, alles umgreifenden Sinn.

Die Nachricht, dass General Lavalle seinen ursprünglichen Plan aufgibt, von Buenos Aires abrückt und sich ins Landesinnere zurückzieht, läutet das blutige Ende des Romans ein. Unsere romantischen Helden sind verloren, wenn sie sich auch noch nicht geschlagen geben. Auch Daniel Bello sieht nun ein, dass der Kampf nur noch vom Exil aus weitergeführt werden könne. Damit rechtfertigt er das Exil seines Autors, der - etwas klüger - wenige Monate zuvor noch rechtzeitig die „Veredas de enfrente“ und damit das rettende Uruguay erreicht hatte. Zugleich erfolgt auch eine Rechtfertigung der Tätigkeit Mármols im Exil als Schriftsteller, wird doch der politische Kampf mit der Feder in der Hand als überaus wichtig dargestellt. ${ }^{50}$

Ein letztes Mal wendet sich sein Roman der schönen Amalia zu und porträtiert sie als Göttin im Spiegel. ${ }^{51}$ Der Blick in den Spiegel ist bei Gustave Flaubert, etwa in seinem Roman Madame Bovary, stets Ausdruck eines letzten Bewusstwerdungsprozesses, findet sich freilich aber bereits früher als Zeichen innerer Vorgänge von Romanheldinnen und geht auf eine lange Literaturgeschichte im Abendland zurück. So blickt Amalia also in den Spiegel; doch die Vögel in ihrem Haus singen nicht mehr und sind verstummt. ${ }^{52}$ Das Leben ist vor dem fatalen letzten Schnitt an ein Ende gelangt.

Die Rose, die Amalia auf ihren Schminktisch stellt, auf ihren „Tocador“, fällt zu Boden. Und die junge Frau erinnert sich an jene zu Boden fallende weiße Rose an jenem Tag, an dem sie Eduardo auf immer ihr Herz schenkte und sich mit seinem Schicksal verband. Nun ist der Tag gekommen, an dem sie ihm ihre Hand geben, ihn also feierlich heiraten wird und sich beider Schicksal unauflöslich miteinander verbindet: Der Kreis des Romans schließt sich, und damit auch der Lebenskreis seiner Romanfiguren. Doch kommt es noch zur Vermählung, kommt

49 Ebda., S. 473.

50 Ebda., S. 479.

51 Ebda., S. $488 \mathrm{f}$.

52 Ebda., S. 491. 
es noch zum Vollzug jener Verbindung, die sich als nationale Allegorese Argentiniens lesen lässt?

José Mármols Roman hatte mit Eduardos Kampf gegen die Blutschergen der Mazorca begonnen; und er endet mit dem Kampf aller positiven Figuren gegen die finsteren Gesellen dieser blutrünstigen staatsterroristischen Vereinigung. Weder die britische Botschaft noch die Kirche schützen die rechtschaffenen Unitarier vor der Grausamkeit der Anhänger des Diktators. Die europäischen Mächte, die in der historischen Entwicklung eben noch eine koloniale Bedrohung dargestellt hatten, erscheinen plötzlich als Hoffnungsträger der Unitarier. Doch sie können nicht mehr eingreifen und auch die englischsprachige Welt ist verstummt.

Allein ein Mister Slade, der typisch amerikanische Konsul der USA in Argentinien, hat trotz seines Phlegmas das Herz auf dem rechten Fleck und ist - Gewehr in der Hand - bereit zum Widerstand gegen die nationale Diktatur. Es handelt sich um das erste Auftauchen eines US-amerikanischen Gesandten, dessen Figur im hispanoamerikanischen Roman des 19. wie des 20. Jahrhunderts zur festen Größe werden wird. Dieser Slade, so die Fußnote des Romans, brachte über hundert Argentinier in seinem US-amerikanischen Konsulat unter, wobei diese freilich für die fälligen Unterhaltskosten aufkommen mussten. Doch dadurch waren sie zumindest vorläufig vor den Nachstellungen der Diktatur geschützt. Angesichts von deren Rücksichtslosigkeit trügt diese Sicherheit freilich, und selbst der wackere Mister Slade wird unter ungeklärten Umständen den Tod finden. Lange, historisch dokumentierte Listen argentinischer Ermordeter begleiten diesen Schlussteil des Romans. ${ }^{53}$ Für Tausende sind alle Hoffnungen auf eine Rettung aus den blutigen Fängen der Rosas-Diktatur dahin.

Doch noch ist der Roman nicht zu Ende, noch immer gibt es Hoffnung darauf, dass unser romantisches Liebespaar die Gewalt und Brutalität der argentinischen Diktatur überleben wird. José Mármol tut alles dafür, den „Suspense“ zu verlängern: Ein allerletztes Mal tritt Amalia vor den Spiegel und wird mit den biblischen Schönheiten Israels verglichen. ${ }^{54}$ Die Argentinierin rückt damit in eine alttestamentarische Geschichte ein, wird gleichsam biblisch semantisiert und sakralisiert. So sind es keine indigenen Schönheiten, in deren Abfolge sie gestellt wird: Ihr Rückbezug erfolgt stets transatlantisch, mit Blick auf Europa und das Abendland. Auch hieran kann man deutlich eine signifikante Situierung innerhalb des von uns skizzierten kulturellen Kräftefelds erkennen.

Amalia blickt also noch ein letztes Mal in den Spiegel und erkennt sich in ihrer ganzen Gestalt. Sie bereitet sich auf die Hochzeit vor; eine Szenerie, die in gewis-

53 Ebda., S. 510.

54 Ebda., S. $516 \mathrm{f}$. 
ser Weise an die Hochzeitsszene in Balzacs Les Chouans erinnert, wo es ebenfalls kurz vor dem tragischen Ende zu einer Heirat in extremis kommt. Noch ist eine letzte Hoffnung intakt, ins Exil nach Montevideo zu gelangen. José Mármols Beispiel selbst bestätigte diese letzte Hoffnung, erreichte er doch erst im November 1840 das rettende Ufer der uruguayischen Republik. Unsere romantische Heldin freilich ist bereits extrem bleich und fürchtet sich vor jedem Schlagen der Uhr, als könnte dieses den letzten Schlag der Diktatur ankündigen. Die Blätter der weißen Rose fallen zu Boden; und wie in der obigen Szene angekündigt, bedeckt der Brautschleier nun beide Liebende. ${ }^{55}$

Was geschehen soll, geschieht nun: Schon tauchen die Federales auf, gehen unmittelbar zum Angriff über, dringen in das Haus ein, zerstören dessen Inneneinrichtung, auch den Spiegel, in dem sich Amalia in ihrer Schönheit ein letztes Mal gegenübergetreten war. ${ }^{56}$ Von der englischen Literatur, den europäischen Literaturen, die sich in ihrer Bibliothek befanden, wird nichts übrig bleiben: Die argentinische Barbarei löscht die Zeugnisse europäischer Zivilisation aus. Die teuflische Übermacht der Federales ist erdrückend; und so flieht die Seele des tödlich verwundeten Eduardo bald schon zu Gott. Amalia selbst sinkt blutüberströmt ins bereits blutige Bett: Es sind wahrhaftige „Bodas de sangre“, die sich vor den Toren der argentinischen Hauptstadt zutragen. Ihrem treuen Diener, der ehemals General Belgrano zu Diensten war, wird die Kehle durchgeschnitten. Das überraschende Auftauchen von Daniels Bellos Vater, der über beste Kontakte zu Diktator Rosas verfügt, kann das Blutbad nicht mehr verhindern: Tot sinkt Daniel in seine Arme. ${ }^{57}$ Nach diesem Maximum an vergossenem Blut, das an Esteban Echeverrías El Matadero und seine bluttriefende Schlussszene erinnert, endet der gesamte Roman in einer einzigen Katastrophe. Damit sind nun alle Hoffnungen und politischen Träume ausgeträumt, bevor noch ein kurzer Epilog den Band abschließt.

Mit dem Ende der Rosas-Diktatur geht 1852 eine große Phase der argentinischen Literatur zu Ende. Die Proscriptos kehren zurück und die Quellen der von ihnen verfassten und überraschend homogenen Exilliteratur versiegen. Diese für die Entwicklung der lateinamerikanischen Literaturen so wichtige Exilliteratur hatte zum ersten Male ihre Schrecken, aber auch ihre produktive Größe gezeigt. Damit waren zugleich die Grundlagen für die Narrativik und Essayistik der hispanoamerikanischen Literaturen nachkolonialen Typs gelegt. In Argentinien wurde mit dem Aufbau eines nach europäischen Begriffen modernen National-

55 Ebda., S. 522.

56 Ebda., S. 526.

57 Ebda., S. 529. 
staats begonnen, dessen kulturelles Projekt unbeirrbar am ersten Pol unseres kulturellen Schemas ausgerichtet blieb. Die nach Buenos Aires zurückgekehrten Exilanten versuchten mit aller ihnen nun zur Verfügung stehenden Macht, den Einfluss indigener wie schwarzer Bevölkerungsgruppen, aber auch der Gauchos und ihrer Volkskultur zurückzudrängen. Die Grundlagen des politischen Systems Argentiniens, das wie in den meisten Ländern des Subkontinents nicht an Kompromissen und politischen Konsensbildungen ausgerichtet ist, waren nunmehr gelegt.

José Mármols Schreiben war zweifellos bevorzugt an englischsprachiger Literatur ausgerichtet. Ich möchte an dieser Stelle unserer Vorlesung nicht die historische Entwicklung der Beziehungen zwischen den spanischsprachigen Literaturen und der englischsprachigen Welt weiterverfolgen, so spannend eine weitere Untersuchung dieser intertextuellen Traditionslinie auch wäre. Denn wir könnten dabei etwa im Bereich der hispanoamerikanischen Literaturen sehr schön verfolgen, wie stark sich immer wieder bestimmte Konstellationen der englischsprachigen Literaturen insbesondere in der kulturellen Area des Cono Sur auf Entwicklungen im Literatur- und Kulturbereich auswirkten.

Nennen möchte ich beispielsweise den tiefgehenden Einfluss, der von der englischen Literatur der Jahrhundertwende - namentlich Oscar Wilde - auf die Dichter und Prosaschriftsteller des hispanoamerikanischen Modernismo ausging; eine Wirkung, die in ihren Konsequenzen kaum überschätzt werden kann. Sicherlich ist ebenso die Präsenz einer langen literarischen Tradition anzufügen, denken wir nur an William Shakespeare und José Enrique Rodós Ariel, mit dem wir uns gegen Ende unserer Vorlesung beschäftigen werden. Doch auch die direkte Wirkung zeitgenössischer englischsprachiger Literatur war höchst bedeutungsvoll.

Sie wurde zugleich ergänzt und gegenbalanciert durch eine starke Präsenz, die dabei zum ersten Mal auch US-amerikanischen Dichtern und Philosophen zukam. Zu nennen wären hier an der Jahrhundertwende im Bereich der Lyrik insbesondere der Dichter Walt Whitman, der übrigens gerade auch durch einen hispanoamerikanischen Modernisten wie José Martí zum ersten Mal in die europäische Welt der spanischsprachigen Literaturen eingeführt wurde. Im Bereich der Philosophie dürfte niemand stärker als Ralph Waldo Emerson auf die Entfaltung der Naturkonzeption im Modernismo und weit darüber hinaus eingewirkt haben. Am Ausgang des 19. Jahrhunderts verstärkten sich nicht nur die transatlantischen Literaturbeziehungen erneut, sondern wuchsen auch die intertextuellen Relationen zwischen dem Süden und dem Norden des Kontinents.

Nehmen wir die Präsenz der englischsprachigen Literatur und Philosophie in Frankreich, so ist das französische 18. Jahrhundert ohne die Aufklärungsphilosophie Englands überhaupt nicht zu denken. Ein Voltaire hat nicht nur wie viele 
andere Franzosen England als zeitweiliges Fluchtland genutzt, sondern auch dessen Philosophie stark reflektiert: So wäre er ohne David Hume oder John Locke in der uns bekannten Form nicht zu denken - auch wenn wir hier in Potsdam selbstverständlich den Einfluss von Friedrich II. und des preußischen Hofes nicht gering achten wollen!

Die prägende Wirkung des englischsprachigen Romans gerade auch mit Blick auf die Subgattung des historischen Romans ist im entstehenden Lateinamerika ohne das Vorbild Walter Scotts nicht vorstellbar. Diese Aussage gilt nicht nur für den hispanoamerikanischen Roman, sondern auch für die Entwicklung des Romans in Spanien wie in Frankreich oder Italien. Ebenso ist zum Fin de siècle hin ein John Ruskin oder Oscar Wilde von zentraler Bedeutung für die französische Jahrhundertwende, so dass selbst Marcel Proust ohne Ruskin in seiner ästhetischen Entwicklung sicherlich einen anderen Weg eingeschlagen hätte. Wir könnten diese Liste immer weiter ins 20. Jahrhundert verlängern und ihr immer wieder neue Namen anfügen: Gabriel García Márquez war selbstverständlich ein großer Leser der Südstaatenepen William Faulkners, deren Strukturen sich ohne weiteres in seinen Romanen ausmachen lassen. Für die entstehenden Literaturen der Welt ist ab der zweiten Hälfte des 20. Jahrhunderts die Referenz und Reverenz gegenüber englischsprachigen Texten nicht mehr anhand von Einzelbeispielen zu erfassen.

Die externe Relationalität zur englischsprachigen Welt betrifft nach wie vor auch Gattungen wie etwa die „Hard boiled“ Genres des Kriminalromans, wo wir seit Edgar Allan Poe von Beginn an eine klare US-amerikanische Zentrallinie ausfindig machen können. Sie ist von enormer Bedeutung für die italienische (Leonardo Sciascia) oder spanische Literatur (Manuel Vázquez Montalbán), aber auch für die hispanoamerikanischen Literaturen in Gestalt etwa des zeitgenössischen chilenischen Kriminalromans.

Anstatt diese Überlegungen in unserer Vorlesung noch weiter auszubuchstabieren, möchte ich an dieser Stelle nun vorschlagen, bei der externen Relationalität zu bleiben, zugleich aber den Blick kurz auf die deutschsprachige Welt zu öffnen. Von grundsätzlicher Bedeutung ist in dieser Beziehung einmal mehr der Ausgang des 18. und vor allem der Beginn des 19. Jahrhunderts; mithin ein Zeitraum, bei dem man von einer entscheidenden Take-off-Phase der europäischen und der außereuropäischen Modernen sprechen kann. Ich möchte als Beispiel hierfür nicht ein ähnlich asymmetrisches Exempel wählen, sondern in diesem Falle auf die Beziehung zwischen der französischen und deutschen Literatur während dieser Sattelzeit deuten. Auf diesem Gebiet haben wir bereits die überragende Rolle wahrgenommen, welche das gesamte Werk der Germaine de Staël gerade für die deutsch-französischen Beziehungen spielte. Es war auch für die Vermittlung Deutschlands in die spanischsprachige Welt über Frankreich hinaus 
von maßgeblicher Bedeutung. Nicht zu unterschätzen sind für den transatlantischen Raum aber auch Figur und Werk Alexander von Humboldts, dessen Schriften nicht nur bei amerikanischen Kreolen den Wunsch nach politischer Unabhängigkeit befestigten, sondern dessen Schreiben auch von enormem Einfluss auf die Literaturen in Lateinamerika war. Es ist gerade diese literarische Signifikanz, diese Bedeutung des Preußen weniger als Naturforscher denn als Schriftsteller, die sich immer wieder wie ein roter Faden durch die Literaturgeschichten zieht und Humboldt zu einer zentralen transatlantischen Vermittlungsfigur zwischen den Literaturen werden lässt.

Humboldt schrieb nicht nur auf Deutsch, sondern vor allem auf Französisch. Vergessen wir nicht, dass Frankreich für die Romanischen Literaturen der Welt über eine lange Zeit mit Paris als der Hauptstadt des 19. Jahrhunderts die zentrale Funktion einer internationalen Drehscheibe spielte! Vieles von der deutschen und deutschsprachigen Literatur und Philosophie, das wir in Lateinamerika im 19. wie im 20. Jahrhundert beobachten können, ist sozusagen durch die „Porte de Paris“ gegangen, also durch den französischen Zoll. Um folglich besser zu verstehen, wie die deutsche Philosophie - neben der Linie, die über Alexander von Humboldt verläuft - nach Amerika und insbesondere in die spanisch- und portugiesischsprachige Welt gelangte, gibt es kein besseres Beispiel als Germaine de Staël. Sie ist jene Brückenbauerin zwischen der französisch- und der deutschsprachigen, aber auch der hispanophonen Welt, die wir bereits vor allem im europäischen Kontext kennengelernt haben. Wir können uns an dieser Stelle nicht nochmals zu Madame de Staël wenden, müssen uns aber noch einmal vor ihr verbeugen, da ihre internationale und transatlantische Rolle wohl erst in den kommenden Jahrzehnten adäquat beleuchtet werden kann.

Doch nun ist es an der Zeit, die kulturelle Area in Lateinamerika zu wechseln und vom Süden des Kontinents in den Norden, genauer in jenen Inselbereich zu gehen, den wir gemeinhin als Karibik bezeichnen! Wir wollen uns im Bereich der Inselkaribik anhand zweier unterschiedlicher Beispiele einen Eindruck davon verschaffen, wie sich in dieser Area die intertextuellen Relationen verhielten und welche entscheidenden Literatur- und Kulturbeziehungen die spanischsprachigen Literaturen dort auf transareale und zum Teil transkulturelle Weise prägten. 